Química Verde, Economia Sustentável e Qualidade de Vida Ferreira, V. F.; da Rocha, D. R.; da Silva, F. C.

Rev. Virtual Quim., 2014, 6 (1), 85-111. Data de publicação na Web: 12 de outubro de 2013 http://www.uff.br/rvq

\title{
Green Chemistry, Sustainable Economy and Quality of Life
}

Abstract: Despite the early problems linked to industrial activities related to chemistry date back to the early twentieth century, and issues such as green chemistry and sustainability have been already discussed in academic and industrial environments. Green chemistry is good for the environment, human health and the economy, but there are still many mysteries in the "green field". In this article, the authors attempt to repackage the "green" concept of the chemistry focused on the needs of developing new processes and broader reflections on global and sustainable economy and quality of life.

Keywords: Green chemistry; sustainability; quality of life; environment.

\section{Resumo}

A imagem da Química tem sido relacionada a problemas oriundos de atividades industriais desde o início do século XX. Seus reflexos no meio ambiente reforçam a necessidade da redução de riscos em produtos e processos, e temas como Química Verde e sustentabilidade vêm sendo discutidos nos meios acadêmicos e industriais. A Química Verde é boa para o meio ambiente, a saúde humana e economia, mas ainda existem muitas "sombras" no verde. Neste artigo, os autores discutem o conceito "verde" da Química, voltado para o desenvolvimento de novos processos, e de uma reflexão mais ampla e global sobre economia sustentável e qualidade de vida.

Palavras-chave: Química verde; sustentabilidade; qualidade de vida; meio ambiente.

\footnotetext{
* Universidade Federal Fluminense, Departamento de Química Orgânica, Instituto de Química, Campus do Valonguinho, CEP 24020-150, Niterói-RJ, Brasil.

M cegvito@vm.uff.br

DOI: $10.5935 / 1984-6835.20140008$
} 


\section{Química Verde, Economia Sustentável e Qualidade de Vida \\ Vitor F. Ferreira, * David R. da Rocha, Fernando de C. da Silva}

Universidade Federal Fluminense, Departamento de Química Orgânica, Instituto de Química, Campus do Valonguinho, CEP 24020-150, Niterói-RJ, Brasil.

\section{* cegvito@vm.uff.br}

Recebido em 2 de fevereiro de 2013. Aceito para publicação em 6 de outubro de 2013

\section{Introdução}

2. Sustentabilidade como um grande guarda-chuva da sociedade

3. Química, uma ciência Central

4. Química Verde e suas práticas benignas

4.1. Eletrossíntese Orgânica

4.2. Reações em um único vaso reacional (one-pot reaction)

4.3. Reação de metátese de olefinas

4.4. Reações multicomponentes

4.5. A vida é mais bela com os corantes

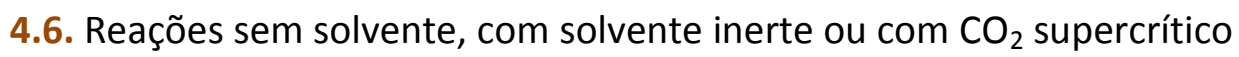

5. O uso de biomassa renovável no contexto atual

6. A transformação do modo de vida com o uso dos biocombustíveis

7. A Talidomida e a revolução dos fármacos

8. Práticas passadas e algumas desastrosas

9. Conclusões

\section{Introdução}

"A ciência domina a vida moderna. A máquina, produto da ciência, marca o ritmo da vida contemporânea. As descobertas científicas influenciam a nossa filosofia e a nossa religião. É impossível entender o mundo moderno sem o estudo da ciência." (Dietz, H. W. The Studyof Science, 4a Ed., 1936).
A 63ạ Assembleia Geral das Nações Unidas (ONU) decretou o ano de 2011 como "Ano Internacional da Química". A escolha teve como base o 100 aniversário do Prêmio Nobel em Química (1911), laureado a Marie Sklodowska Curie (1867-1934), que descobriu os elementos rádio ( $\mathrm{Ra}$ ) e polônio (Po) e investigou a natureza de seus compostos. Este foi seu segundo prêmio, já que o primeiro Nobel foi outorgado em Física, em 1903, juntamente com Pierre Curie e Henri Becquerel (Figura 1), pelos estudos dos 
fenômenos de radiação, descobertos por Becquerel.

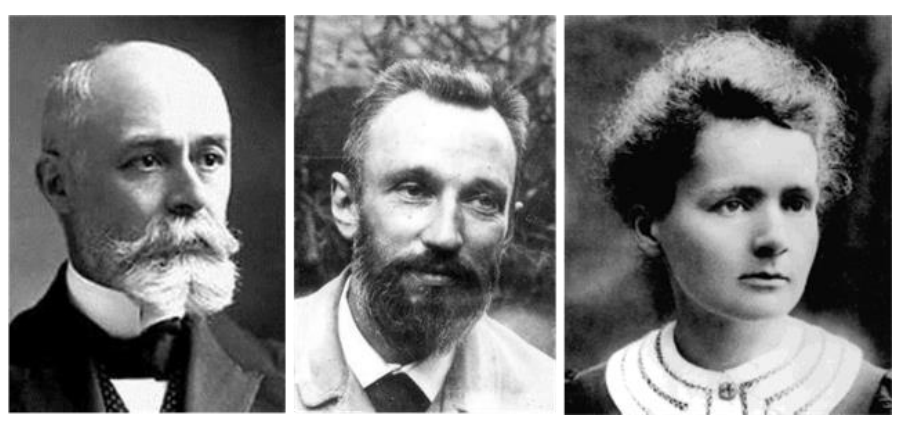

Figura 1. Henri Becquerel, Pierre Curie e Marie Sklodowska

Essa ação fez com muitos pesquisadores, agências de fomento, sociedades científicas, conselhos de classe, universidades e etc., se mobilizassem para pensar como as pessoas veem a Química e a percebem em suas vidas. o "Ano Internacional da Química" foi um catalisador para uma reflexão mais ampla e global sobre economia sustentável e qualidade de vida. Não há como negar que o aumento da expectativa de vida da nossa espécie está relacionada com o desenvolvimento da Química, que contribuiu com medicamentos, vacinas, fertilizantes e defensivos agrícolas para a produção de alimentos em grande escala, dentre outros aspectos positivos.

Um dos pontos mais importantes do "Ano Internacional da Química" foram as discussões sobre como fazer uma Química de modo sustentável em diversos aspectos, como aqueles relacionados às reações, produção industrial, economia dos processos e àqueles relacionados ao meio ambiente, pois é inegável que em todas as atividades industriais há pelo menos um conexão com a Química.

A imagem da Química tem sido relacionada a problemas oriundos de atividades industriais desde o início do século $X X$. Seus reflexos no meio ambiente reforçam a necessidade da redução de riscos em produtos e processos, e temas como Química Verde e sustentabilidade vêm sendo discutidos nos meios acadêmicos e industriais. A Química Verde é boa para o meio ambiente, para a saúde humana e economia, mas ainda existem muitas "sombras" no verde.

Há tempos que o ramo da Química Ambiental vem alertando sobre os prejuízos que os processos químicos podem causar ao meio ambiente. O principal paradigma da Química Verde é reduzir ou eliminar o uso ou a geração de substâncias perigosas durante $o$ planejamento, manufatura e aplicação de produtos químicos. Essa abordagem é importantíssima para a proteção ambiental e gestão de materiais que sejam tóxicos e de ciclo longo de vida. A Química Verde incentiva uma produção mais limpa e com menos poluentes industriais, garantindo que os fabricantes assumam uma maior responsabilidade para os produtos que eles produzem.

De forma similar, a questão da biodegradabilidade dos produtos deveria ser igualmente importante e parte integrante do projeto de desenvolvimento de um produto. Aqueles que resistem à biodegradação permanecem no meio ambiente, causando efeitos tóxicos, alguns dos quais não podem ser conhecidos ou previsíveis logo no início. ${ }^{1}$ Produtos bioacumuláveis persistentes são de grande preocupação, já que tendem a se acumular nos tecidos de peixes, animais, plantas (e cada vez mais concentrados à medida que sobem na cadeia alimentar). Os sintomas de contaminação podem ainda se 
manifestar após várias gerações a partir do contato inicial com a substância tóxica. 0 DDT (dicloro-difenil-tricloroetano) é um exemplo clássico e que mostra esse fato. ${ }^{2}$

A necessidade de reações ambientalmente amigáveis é tão importante que a atitude ecofriendly consciente fez com que os químicos Paul Anastas e John C. Warner postulassem os 12 princípios da Química Verde, em 1998, ${ }^{3}$ a saber: 1. Prevenção; 2. Economia Atômica; 3. Síntese de Produtos Menos Perigosos; 4. Modelo de Produtos Seguros; 5. Solventes e Auxiliares mais Seguros; 6. Busca pela Eficiência de Energia; 7. Uso de Fontes Renováveis de Matéria-Prima; 8. Minimização da Formação de Subprodutos; 9. Catálise; 10.Desenho para a Degradação; 11. Análise em Tempo Real para a Prevenção da Poluição; 12. Química Intrinsecamente Segura para a Prevenção de Acidentes.

Nesse artigo, os autores revisitam alguns desses temas e discutem questões relacionadas à Química Verde, como ela contribui para uma economia sustentável e para a qualidade de vida da população, a

partir do ponto de vista destes autores.

\section{Sustentabilidade como um grande guarda-chuva da sociedade}

A sustentabilidade não deve ser encarada como se fosse uma previsão, mas como uma realidade e uma vivência cotidiana de todos.

Muitas das previsões não se sustentam devido aos vícios de origem e à falta de visão de quem as faz. Um exemplo foi a do físico britânico William Thomson (Figura 2), também conhecido como Lord Kelvin (18241907), que afirmou ser impossível a construção de uma máquina voadora mais pesada do que o ar. Ele estava equivocado já que, em 1906, Alberto Santos Dumont (Figura 2) voou pela primeira vez em Paris. $O$ cientista inglês errou porque viveu a maior parte de sua vida num século de limitado progresso técnico e comunicação precária, diferentemente do atual, apesar de muitos cientistas ainda viverem no século XIX.

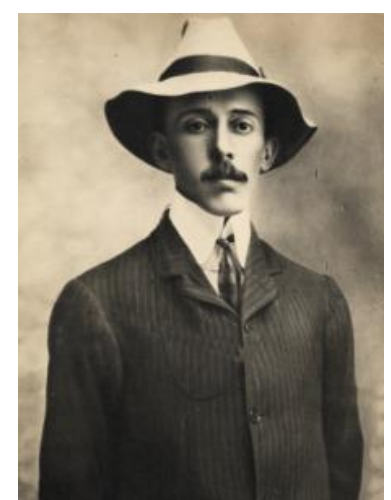

Figura 2. William Thomson (Lord Kelvin) e Alberto Santos Dumont

Neste contexto, a sustentabilidade deveria ser o grande guarda-chuva de proteção da sociedade. Ela não pode relacionada apenas, como sugere uma visão mais simplificada, à emissão de gases para a atmosfera e ao aquecimento global. $O$ termo foi usado pela primeira vez em 1987, no Relatório Brundtland da Organização das
Nações Unidas, com a intenção de focalizar um conjunto de ações que deveriam atender as necessidades humanas dos países com economia estável, a utilização da energia e de recursos de forma eficiente e para uma sociedade justa, sem comprometer as gerações futuras e suas necessidades. Quantos aos materiais, seria desejável que 
fossem produzidos a partir de recursos renováveis e que, ao final de sua utilização, fossem passíveis de reciclagem ou facilmente biodegradáveis em substâncias inofensivas ao ambiente. Com conceitos corretos, faltava incluir na ideia de sustentabilidade os países em desenvolvimento, onde outros problemas atropelam estas questões.

Uma visão mais completa é que a sustentabilidade seja uma cadeia de ações que eleve os padrões ambientais, econômicos e sociopolíticos da população. Assim, tudo está conectado e é interdependente, sendo o cidadão, governo e setor privado os agentes centrais que devem manter o equilíbrio entre água, ar, solo, florestas, oceanos, etc. Não adianta estar atento apenas a um desses itens. Tudo deve ser pensado e executado quanto aos aspectos de uma cadeia sustentável, caso contrário teremos simplesmente uma sustentabilidade "pintada de verde" (Figura 3). A Química pode ser a solução para muitos problemas de sustentabilidade, mas também pode ser a grande vilã. ${ }^{4}$

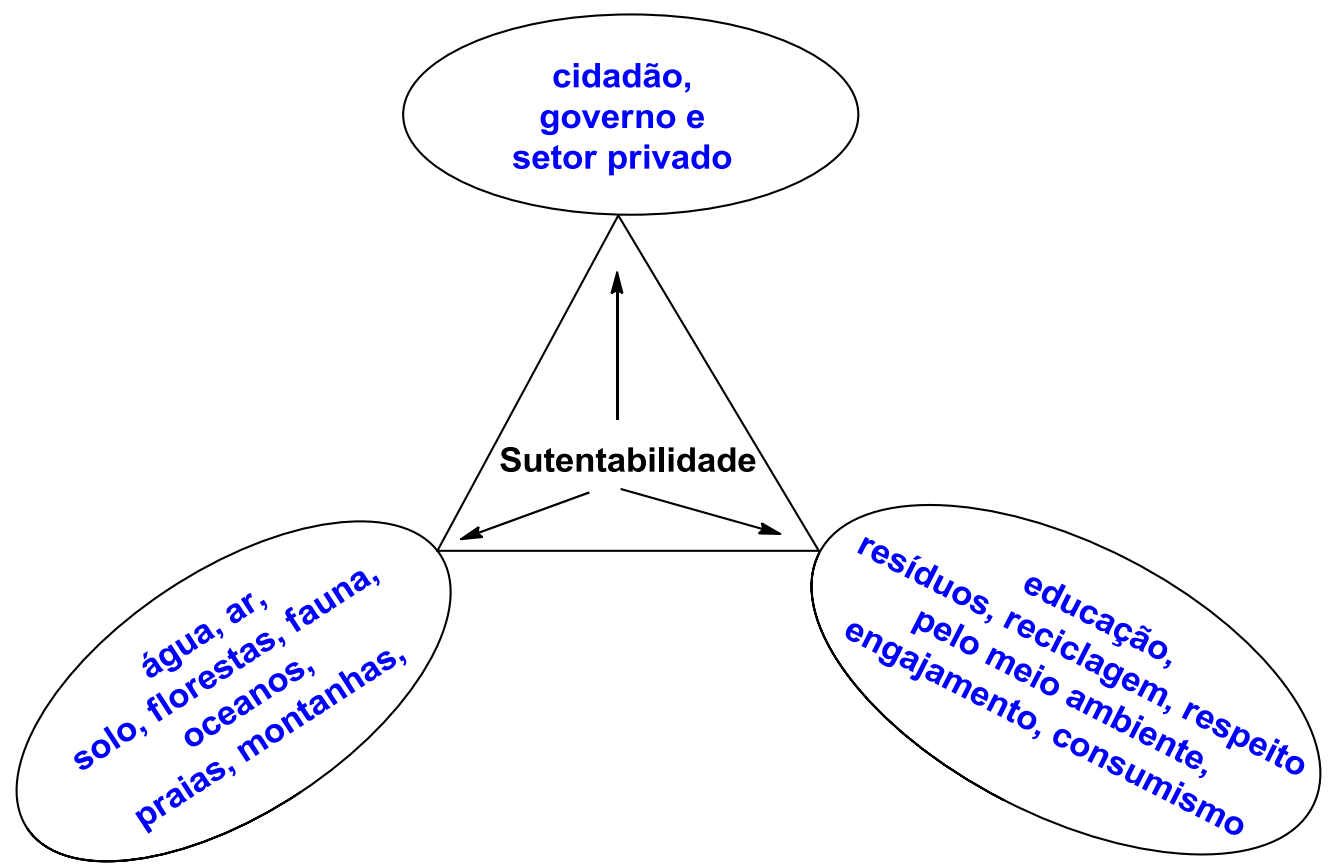

Figura 3. Sustentabilidade e as inter-relações com a sociedade

\section{Química, uma ciência Central}

A Química é a base de tudo e tem o potencial para criar novos materiais $\mathrm{e}$ produtos mais adequados às necessidades do homem, menos agressivos e com menor ciclo de vida no meio ambiente. É capaz de criar substâncias e materiais nunca sonhados. A Química Verde, por sua vez, busca projetos com aplicações mais amigáveis ao ambiente e ao mesmo tempo visa à preservação da vida

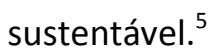

Atualmente, a Química é uma ciência de interfaces onde estão envolvidas diversas áreas como a catálise, biocatálise, ciência dos materiais, genética química, medicamentos, nanotecnologia, biologia molecular, sistema auto-organizados, genômica, defensivos agrícolas, reconhecimento molecular, etc. Existem muitas outras aplicações e, para complementar esse assunto, recomendamos a leitura do excelente texto produzido pela ABIQUIM ("O que é Química?"), que relata: "A química está na base do desenvolvimento econômico e tecnológico. Da siderurgia à indústria da informática, das artes à 
construção civil, da agricultura à indústria aeroespacial, não há área ou setor que não utilize em seus processos ou produtos algum insumo de origem química". "O que é a Química" e como ela atua foi muito bem definida por Luciana A. da Silva e Jailson B. de Andrade, que nos ensina que: "A Química, de forma ampla, pode ser definida como o ramo da ciência dedicado à observação, transformação e construção, pois o trabalho do Químico geralmente inclui a observação e/ou determinação da estrutura ou composição de espécies químicas presentes nos seres vivos, no ambiente e nos materiais, bem como a transformação e construção de novas moléculas". ${ }^{7}$

Parafraseando o Prof. Eliezer J. L. Barreiro "... sem a Química seria impossível manter a qualidade de vida da humanidade com alimentos, segurança ambiental, longevidade e conforto....". A sentença ilustra a importância da Química em nosso cotidiano e seu papel na qualidade de uma vida longeva e saudável. ${ }^{9}$

A Química tem forte participação no PIB dos países desenvolvidos e o consequente impacto na vida econômica do país devido ao volume de produção, número de empregos gerados e envolvimento com todas as atividades da cadeia produtiva. O setor químico industrial brasileiro movimentou, em 2012, cerca de 38,5 bilhões de dólares. ${ }^{10}$
Alguns exemplos interessantes da inserção e abrangência do setor químico serão discutidos a seguir.

Como uma sala de cirurgia e seus aparatos estão relacionados ao setor petroquímico? Válvulas cardíacas, próteses anatômicas, seringas descartáveis, luvas cirúrgicas, recipientes para soro e a própria glicose do soro, embalagens para coleta e armazenamento de sangue, tubos flexíveis e atóxicos, medicamentos e suas embalagens, desinfetantes, sistema orgânico emissor de luz dos equipamentos cirúrgicos e lâmpadas (OLEDS), dentre outros produtos, são oriundos de matéria prima advinda do beneficiamento do petróleo por processos químicos.

Outro exemplo curioso está no esplendor do carnaval, onde a Química está presente nos tecidos, materiais e nas "tinturas" que embelezam esta grande festa popular brasileira. Nos pigmentos das tintas são encontrados corantes contendo metais, como o cobre, que quando combinado com o ligante ftalocianina gera o corante Azul Monastral (Figura 4). ${ }^{11}$ Com pequenas mudanças no ligante ftalocianina, como a troca de hidrogênio por cloro ou bromo, a cor muda para outros tons de azul ou de verde. Se o metal for trocado outras cores surgirão. ${ }^{12}$

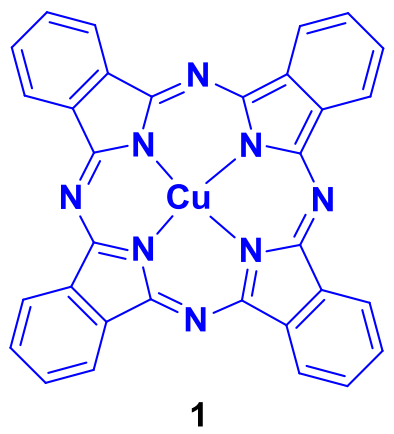

Figura 4. Estrutura do corante Azul Monastral

Na praia, o sol nos aquece e irradia luz em diversos comprimentos de onda através de milhões de reações de fusão nuclear.
Entretanto, é bem sabido que para se proteger dos raios UV, é necessário o uso dos protetores ou filtros solares, óculos e 
barracas. Na água do mar, controlada da poluição, os materiais sintéticos usados em pranchas de surf, roupas de mergulho, cascos de barcos, jet-skis, etc. são produzidos pelas indústrias químicas, ou seja, tem muita Química na praia.

O que dizer dos supermercados? Esses estabelecimentos são verdadeiros laboratórios químicos onde se podem encontrar plásticos, solventes, materiais de limpeza, cera, óleo vegetal, margarina, corante alimentício, creme dental, enxaguante bucal, sabonetes de todos os tipos, sais de banho, xampu, condicionador, desodorante, removedor de maquiagem, creme de barbear, glicerina, amônia, água oxigenada, soda caustica, hipoclorito de sódio e cálcio, loção após barba, hidratante, etc.

\section{Química Verde e suas práticas benignas}

A Química Verde é a parte da Química que envolve o planejamento da síntese e dos produtos químicos. Ela busca evitar a poluição e os problemas ambientais sobre os seres vivos; eliminar os processos químicos prejudiciais ao ambiente e substituí-los por outros menos agressivos, sustentáveis, recicláveis e não persistentes; implementar métodos sintéticos para substâncias de alta eficácia com reduzida toxicidade para a saúde humana e para o meio ambiente; minimizar o uso de energia e usar reagentes preferencialmente na escala catalítica. $O$ resumo destes desafios pode ser visualizado na Figura 5. A seguir serão discutidos alguns processos químicos que se destacam no contexto da Química Verde.

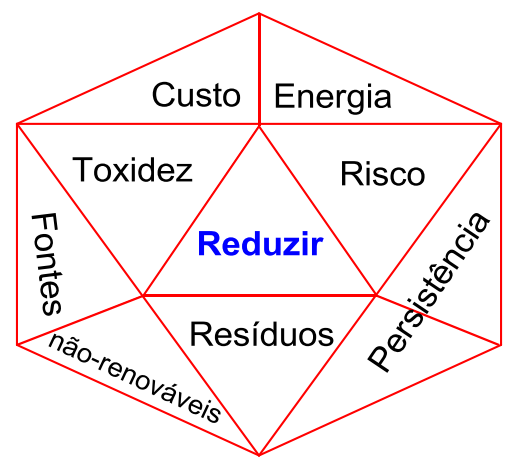

Figura 5. As diversas faces do termo "reduzir" da Química Verde

\subsection{Eletrossíntese Orgânica}

O campo da eletroquímica orgânica tem recebido considerável estímulo devido ao custo plausível da eletricidade e ao seu caráter ambientalmente mais recomendável, em comparação com oxidantes e redutores químicos, em geral poluentes. Controlandose adequadamente o material e a operação dos eletrodos, bem como as condições da solução eletrolítica (solvente, $\mathrm{pH}$, concentração de espécies, etc.), é possível obter alto grau de seletividade para o produto desejado. Adicionalmente, as técnicas eletroquímicas podem ser aplicadas em grande escala para a preparação de material, tanto em escala industrial como de laboratório. São exemplos do uso da eletroquímica industrial a produção de adiponitrila (3) a partir da acrilonitrila (1), intermediário na fabricação do nylon 66 . Recentemente, foi desenvolvido um novo método onde duas reações acopladas, redução da acrilonitrila (2) e oxidação do hidrogênio, produzem somente adiponitrila (3) aproveitando o potencial dos dois eletrodos (Figura 6). ${ }^{13}$ 


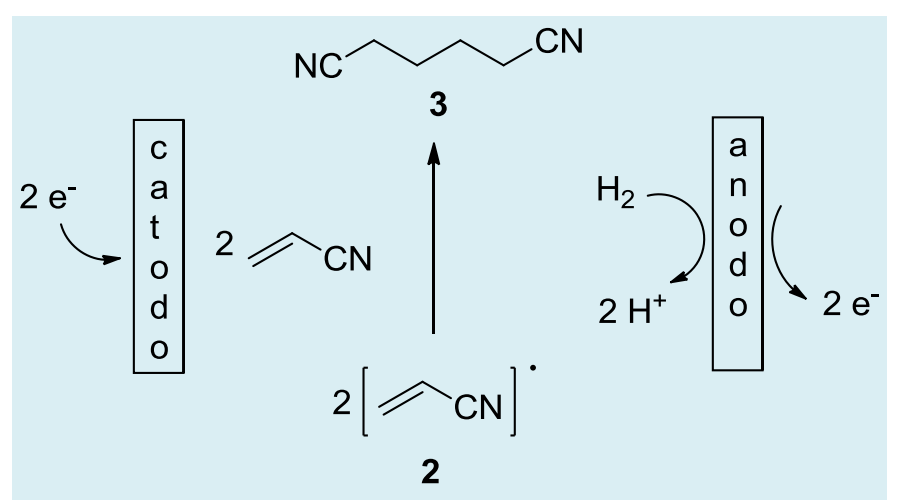

Figura 6. Reações eletroquímicas acopladas para preparação da adiponitrila (3)

\subsection{Reações em um único vaso reacional (one-pot reaction)}

Uma das metodologias mais almejadas pelos pesquisadores envolvidos com a Química Verde são as conversões realizadas em um único vaso reacional (one-pot reaction), com duas ou mais reações acontecendo consecutivamente. É notório que haverá economia de solvente e energia. O exemplo selecionado para ilustrar essas reações é a conversão de 4bromobenzaldeído (4) à respectiva nitrila (6), mediada por DMSO ativado. O procedimento envolve a mistura do aldeído e $\mathrm{NH}_{2} \mathrm{OH} . \mathrm{HCl}$ (na relação de 1:1,1 equivalentes) em DMSO. 0 produto precipita e é isolado por filtração (Esquema 1). ${ }^{14}$

\begin{tabular}{cccccc} 
Solvente & & & & \\
\hline
\end{tabular}

${ }^{\mathrm{a}} \mathrm{A}$ reação foi realizada na presença de $\mathrm{Et}_{3} \mathrm{~N}\left(1,5\right.$ eq.); ${ }^{\mathrm{b}} \mathrm{O}$ material de partida foi recuperado; ${ }^{\mathrm{C}} \mathrm{A}$ reação foi realizada na presença de DMSO (5 eq.); ${ }^{\mathrm{d}} \mathrm{A}$ reação foi realizada na presença de $\mathrm{H}_{2} \mathrm{O}$ (5 eq.)

Esquema 1. Conversão de 4-bromobenzaldeído (4) na respectiva nitrila (6), mediada por DMSO ativado, em único vaso reacional 


\subsection{Reação de metátese de olefinas}

A reação de metátese é uma excelente ferramenta para a síntese orgânica. Ela foi descoberta na década de 1950 na indústria química, segundo observações de Karl Zieger (Prêmio Nobel de Química de 1963), no estudo da polimerização do eteno. Porém, o termo "metátese de olefina" foi introduzido somente 30 anos depois por Nissim Calderon e colaboradores (Calderon et al., 1967). No Instituto Francês do Petróleo, Yves Chauvin compilou os trabalhos de Ernst Otto Fischer (Prêmio Nobel de Química de 1973) sobre a síntese de um complexo de tungstênio, de Giulio Natta, sobre a polimerização do ciclopenteno por abertura do anel catalisada por uma mistura de $\mathrm{WCl}_{6}$ e $\mathrm{AlEt}_{3}$. Porém, quando R. H. Grubbs e colaboradores relataram, em 1992, seu primeiro complexo molecular baseado em rutênio-carbenovinilideno (III), ativo na polimerização de norbonenos e bem estável na presença de solventes próticos, mudou-se completamente a proposta de análise retrossintética para a preparação destes complexos. Para exemplificar essa importante reação, foi selecionada a síntese do antibiótico (-)-griseoviridina (8), realizada por Meyers e colaboradores. A etapa mais importante na síntese total desse antibiótico e seu epímero em C8 foi realizada por metátese do tipo RCM, com alta diastereosseletividade trans em 2 e 2', formando um anel com 23 membros (Esquema 2). ${ }^{15}$<smiles>C=C/C=C/[C@H]1C[C@@H](Cc2nc(C(=O)SC[C@@H]3NC(=O)C(C(=O)NCC=C)=CC[C@@H](C)OC3=O)co2)O[C@@H](C)O1</smiles>

Mes $=$ grupo mesitil<smiles>C[C@H]1CC=C(SC[C@@H]2NC(=O)c3coc(n3)C[C@H](O)C[C@@H](O)/C=C/[C@H]3CCNC(=O)[C@@H]32)C(=O)O1</smiles>

(-)-griseoviridina $(\mathbf{8})$

Esquema 2. Etapa chave na síntese do antibiótico (-)-griseoviridina através de reação de metátese.

\subsection{Reações multicomponentes}

As reações multicomponentes (RMCs) são caracterizadas como sínteses convergentes, partindo de três ou mais reagentes, que preferencialmente transferem todos os átomos dos reagentes aos produtos, sendo caracterizada como uma reação de alta economia atômica. Quanto maior o número de reagentes, maior será a possibilidade de diversificar a estrutura dos produtos. ${ }^{16}$ É notável o seu grande interesse na Química Verde e na Química Medicinal, devido a possibilidade de se obter novos compostos por metodologias simples. ${ }^{17}$ Dentre as diversas RMCs selecionou-se a famosa reação de Ugi, já extensivamente estudada quanto ao mecanismo e aplicada na descoberta de novos medicamentos. Na RMC de Ugi, descrita no Esquema 3, foram obtidos derivados de esqueleto mesoiônico do tipo imidazo [1,2- $\alpha$ ]azina(13) obtidos da reação de piridinas ou isoquinolinas (12), anidrido trifluoroacético (9) e diferentes isonitrilas (10). Pode-se observar que as azinas incorporam todos os átomos dos reagentes. ${ }^{18}$ 


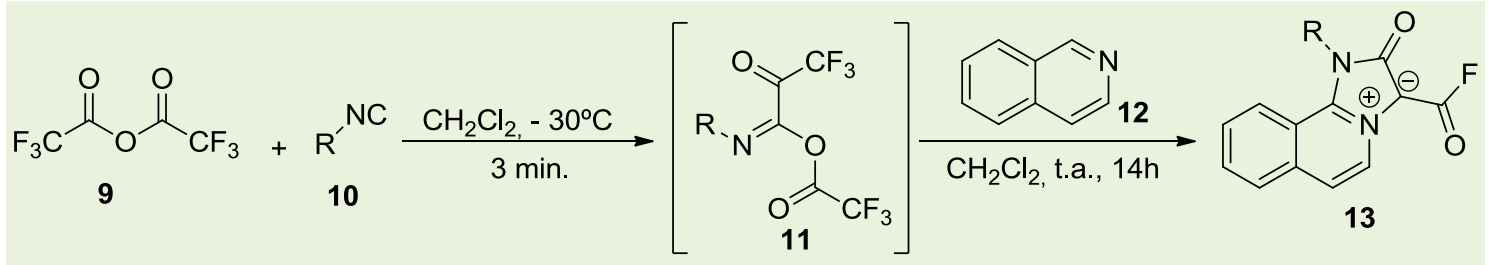

Esquema 3. RMC de Ugi para a preparação de imidazo [1,2- $\alpha$ ]azinas (13)

\subsection{A vida é mais bela com os corantes}

Antigamente, a vida era menos colorida que a atual e poucos eram os materiais disponíveis para colorir, obtidos unicamente de fontes naturais animais ou vegetais. A produção de corantes perpassa a história da humanidade até os dias de hoje, sendo o segmento da química que mais estimulou a curiosidade dos naturalistas e alquimistas. Atualmente, existem corantes para praticamente todos os materiais naturais e sintéticos, inclusive alimentos e medicamentos, onde são utilizados para conferir cor e estimular ou facilitar a ingestão dos mesmos. ${ }^{19}$

Sob a designação de corantes e pigmentos estão incluídos os corantes, alvejantes óticos, pigmentos orgânicos e inorgânicos. A classe dos corantes é a mais numerosa e de maior expressão econômica, compreendendo substâncias solúveis, intensamente coloridas, empregadas para tingir.

Esses aditivos alimentares estão presentes nos alimentos industrializados e a cada dia estão mais presentes na dieta habitual da população.

Talvez o primeiro corante utilizado pelo homem tenha sido o sangue, presente nas pinturas ruprestes. Por volta do ano 3000 a.C., os egípcios já usavam o índigo (14, cor azul), que é retirado da folha de anileira (Indigofera suffruticosa Mill.) e o púrpura de Tyrian (15), obtido de caracóis do Mediterrâneo (Murex brandaris e Murex truculus). Mas a cor púrpura era de exclusividade da família dos faraós. Os egípcios se destacaram no emprego de substâncias corantes naturais das mais diversas origens. A púrpura de Tyrian (15) também foi muito utilizada para tingir a toga dos imperadores romanos e bem mais tarde é que a Europa conheceu o índigo procedente da Índia. Tecidos escarlates eram obtidos pelo tratamento inicial do pano com água de cal ou uma solução de alúmen (óxido de alumínio) e posterior fervura com um extrato da raiz de garança ou ruiva-dostintureiros (Rubia tinctorium), que contém a alizarina (16) em boa quantidade (Figura 7). ${ }^{20}$<smiles>O=C1/C(=C2\Nc3ccccc3C2=O)Nc2ccccc21</smiles>

Índigo (14)<smiles>O=C1/C(=C2\Nc3cc(Br)ccc3C2=O)Nc2cc(Br)ccc21</smiles>

Púrpura de Tyrian (15)<smiles>O=C1c2ccccc2C(=O)c2c1ccc(O)c2O</smiles>

Alizarina (16)

Figura 7. Estruturas dos corantes naturais índigo (14), púrpura de Tyrian(15) e da alizarina (16)

Durante a idade média, a Europa se constituiu no centro do mundo e, portanto, detentora do poder econômico mundial. ${ }^{21,22}$ As sociedades europeias em expansão precisavam de corantes naturais para satisfazer suas necessidades. Com a descoberta da América, e a chegada dos portugueses ao Brasil, o mundo descobriu um 
novo corante vermelho muito utilizado pelos índios brasileiros, que era extraído do paubrasil (Caesalpinia echinata). A árvore do pau-brasil era frondosa, de tronco ferruginoso, com folhas verde-acinzentado, belas flores amarelas, com cerca de 30 metros de altura e se concentrava entre o Rio de Janeiro e o sul da Bahia. ${ }^{23} \mathrm{O}$ pau-brasil já era conhecido como fonte de corante mesmo antes do encontro dos portugueses com o Brasil, pois a espécie Caesalpinia sappan L. das Índias Orientais era comercializada com este fim. Sir Robert Robinson (1886-1975; Prêmio Nobel em 1947) foi quem demonstrou que a brasileína (18), produto de oxidação da brasilina (17), é a substância responsável pela cor vermelha do pau-brasil (Esquema 4). Este corante era usado principalmente para tingir tecidos e como tinta para a escrita. Neste processo oxidativo também é obtida a Hematotoxilina (19).

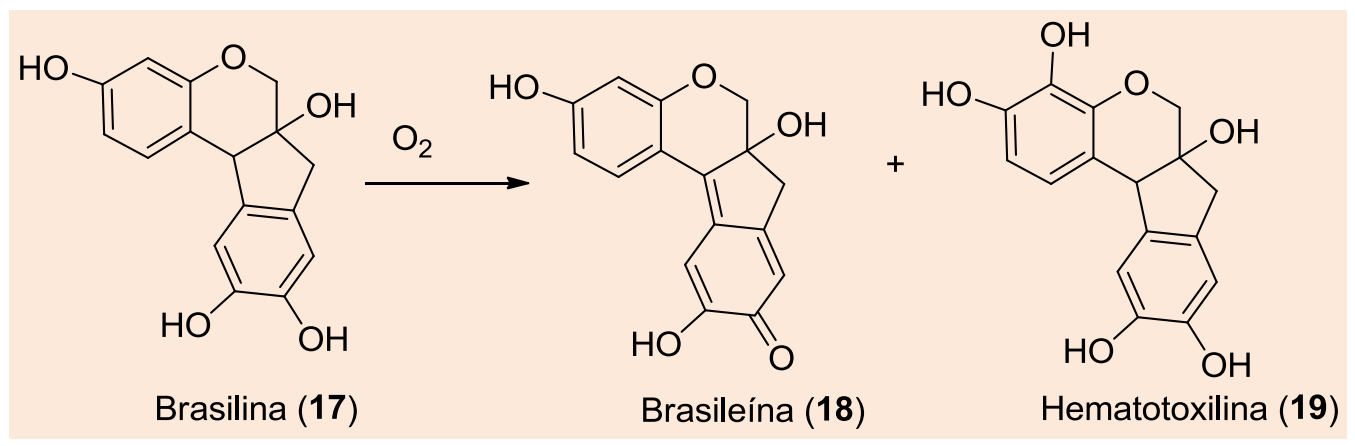

Esquema 4. Corantes vermelho extraídos do pau-brasil

\subsection{Reações sem solvente, com solvente inerte ou com $\mathrm{CO}_{2}$ supercrítico}

Os solventes são fundamentais nos processos químicos. Como usualmente não são incorporados ao produto final, contribuem com uma grande quantidade de resíduo, o que é agravado em processos multietapas devido à presença dos vários solventes e das diversas operações de purificação. Embora, em tese, possam ser reciclados, muito se perde para o meio ambiente antes da sua eliminação.

Sempre que possível os químicos buscam as reações sem solvente, o que é especialmente difícil quando se trata de um processo de aumento de escala. Desta forma, a alternativa é descobrir substitutos que tenham um ciclo de funcional mais verde, reduzindo o impacto ambiental. Neste sentido, podemos citar: a água, ${ }^{24,25}$ os solventes renováveis derivados de biomassa, ${ }^{26}$ os líquidos iônicos ${ }^{27,28}$ e os líquidos supercríticos.

$\mathrm{O} \mathrm{CO}_{2}$, aplicado em escala laboratorial em processos supercríticos, é o mais conhecido de todos. Processos de descafeinização do café, em escala industrial, já são realizados com o uso de $\mathrm{CO}_{2}$ supercrítico (ver em http://www.biotecnologia.com.br/revista/bio 11/fluidos.pdf). Ele exibe propriedades de um alcano líquido e é especialmente útil em reações que envolvem reagentes gasosos, como hidrogenação com $\mathrm{H}_{2}$ (Esquema 5), ${ }^{29,30}$ oxidação com $\mathrm{O}_{2}$ ou hidroformilação com gás de síntese. $\mathrm{O} \mathrm{CO}_{2}$ é um subproduto de vários processos fermentação de biomassas e pode ser obtido em alto grau de pureza. ${ }^{31}$ Assim sendo, ele atende a duas das categorias de solventes apregoadas na Química Verde. 


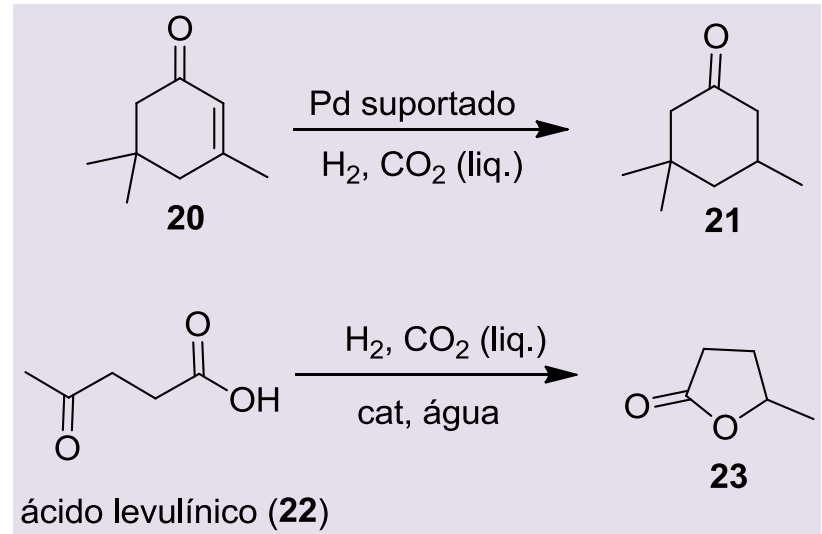

Esquema 5. Exemplos de hidrogenação com $\mathrm{CO}_{2}$ supercrítico

4.6.1. Uso de $\mathrm{CO}_{2}$ como matéria-prima: o caso dos policarbonatos

O policarbonato é um polímero versátil com alta transparência, resistência ao impacto e calor, usado em discos ópticos, aparelhos eletrodomésticos, na eletrônica, peças para automóveis, equipamentos de escritório, e muitas outras aplicações. Cerca de 4 milhões de ton de policarbonato são produzidos por ano em diversas empresas espalhadas pelo mundo, e encontra-se em crescente expansão. Quase todos policarbonatos são fabricados pela reação de monóxido de carbono (CO) e cloro para formar fosgênio (24) que, apesar de ser um gás extremamente tóxico, é um reagente utilizado em diversos processos (Esquema 6). Os inconvenientes para os trabalhadores que lidam com esse gás e os riscos em termos ambientais são bem conhecidos.

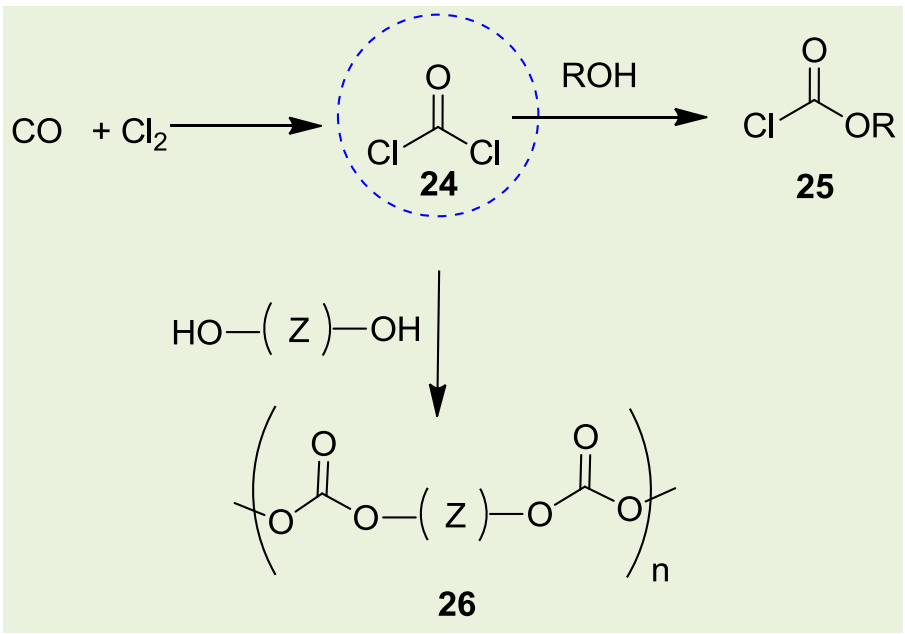

Esquema 6. Versatilidade sintética do fosgênio

Muitos estudos foram realizados visando eliminar o uso de fosgênio (24) nesse processo. A companhia química japonesa AsahiKasei Corporation ${ }^{32}$ desenvolveu e comercializou policarbonato por um processo que não utiliza fosgênio (24) na sua produção. A ideia principal era utilizar dióxido de carbono (blocos C1), ${ }^{33-36}$ o principal gás-estufa e também é tóxico, mas vantajoso por ser barato e abundante. 0 processo utiliza óxido de etileno e $\mathrm{CO}_{2} . \mathrm{O}$ óxido de etileno é um subproduto da síntese 
do etileno e comercializado em larga escala. A reação entre o óxido de etileno $(27)$ e $\mathrm{CO}_{2}$ forma o carbonato de etileno $(\mathbf{2 8})^{37,38}$ que é convertido em carbonato de dimetila (30), depois a carbonato de difenila (31) e então reagido com bisfenol-A (32) para produzir policarbonato polimérico (Esquema 7). Como subproduto é formado o monoetilenoglicol (29) de alta pureza, utilizado em outros processos. O diclorometano usado como solvente foi eliminado, assim como o cloro.

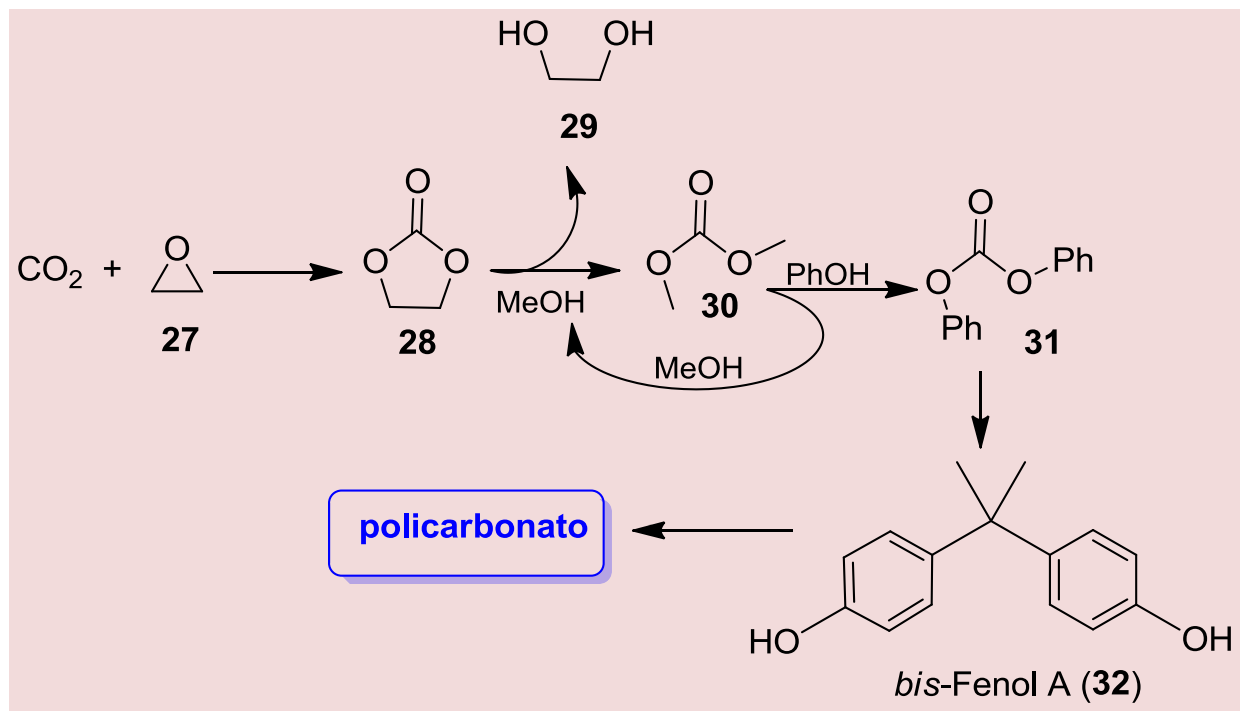

Esquema 7. Produção de policarbonato via $\mathrm{CO}_{2}$

\section{0 uso de biomassa renovável no contexto atual}

A biomassa terrestre renovável tem diversas origens biossintéticas:

1) de baixa massa molecular como açúcares, aminoácidos, lipídios, alcaloides, terpenos, etc.;

2) de alta massa molecular como celulose, hemicelulose, quitina, amido, lignina e proteínas.

Para esse conjunto de biocompostos existem duas alternativas: 1) uso in natura como alimentos, medicamentos, etc. e 2) para a produção de uma variedade de materiais especiais, biocombustíveis e intermediários na química fina. Com algumas pequenas transformações por métodos térmicos, químicos ou biológicos, é possível criar novamente o ciclo e se obter combustíveis sólidos, líquidos ou gasosos ou ainda produtos químicos de maior valor agregado.

O debate e a preocupação sobre o uso de combustíveis fósseis estão em todos os meios de comunicação, devido aos problemas ambientais e ao aquecimento global. Dentro desse contexto, a utilização de biomassa renovável surge como uma alternativa duradoura e cada vez mais importante para o futuro. Mas é nos diversos produtos químicos que reside $o$ grande interesse no seu aproveitamento nos últimos anos. ${ }^{39}$ Processos térmicos, químicos e biotecnológicos já estão disponíveis para a transformação de certas biomassas em moléculas úteis, da mesma forma que a química orgânica fez com o petróleo, no século passado. Apesar de ainda serem em número reduzido, é possível antecipar que neste século observaremos o crescimento das indústrias químicas baseadas em biomassa, paralelamente ao declínio da indústria petroquímica, o que ocorrerá com significativas vantagens ambientais. Diante desse cenário, o Brasil deveria desenvolver 
suas próprias tecnologias capazes de transformar as suas biomassas renováveis e abundantes em intermediários de química fina ou insumos básicos para a indústria química, pois é fato que as matérias-primas fósseis se esgotarão. ${ }^{40}$

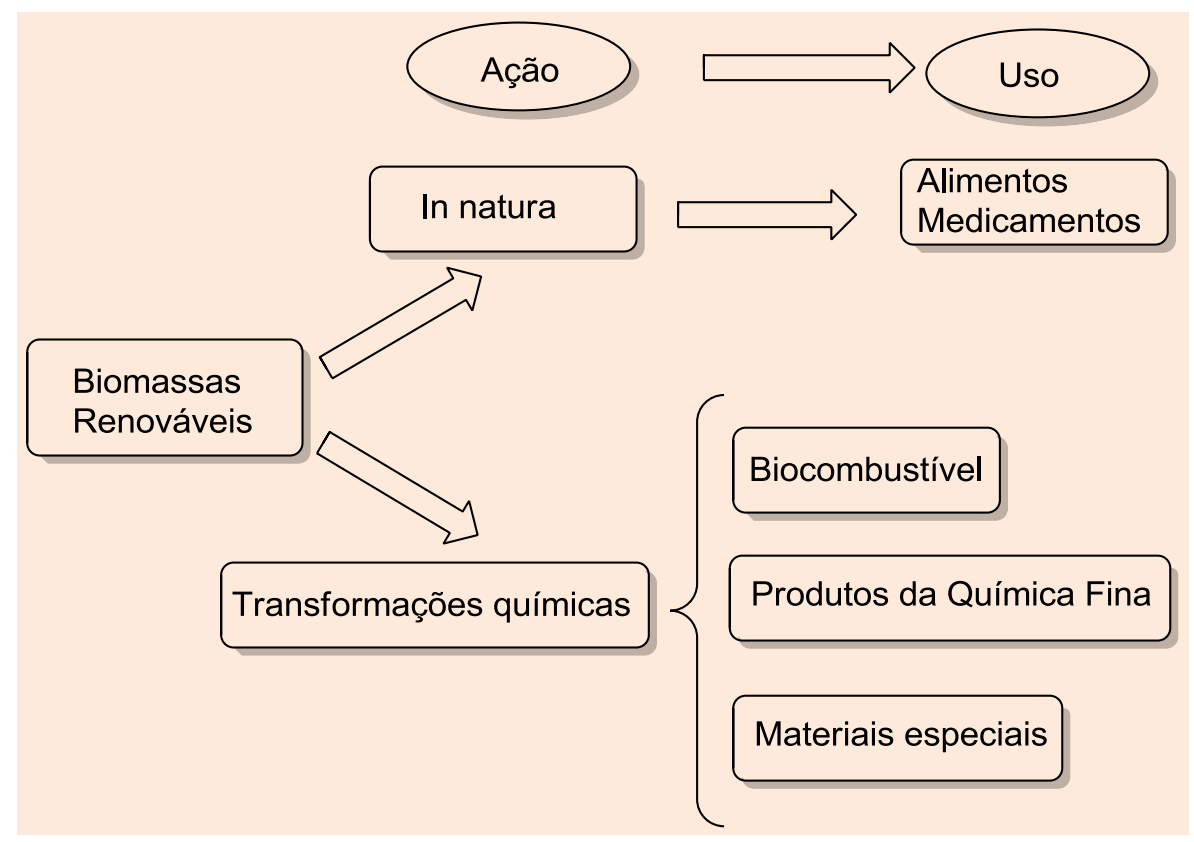

Figura 8. Biomassa renovável: ações e usos em prol da humanidade

Vamos analisar o caso particular da celulose (33) e como ela pode ser aproveitada na obtenção de moléculas de baixa massa molecular, úteis na Química Fina, já que o Brasil é um grande produtor de celulose a partir do eucalipto. Vale destacar ainda que, depois da celulose, a quitina (34) é o segundo biopolímero mais abundante renovável na Terra (Figura 9), amplamente disponível a partir de uma variedade de fontes, como os crustáceos do tipo camarão, caranguejo, lagosta, etc. A síntese anual de quitina em ecossistemas de água doce e marinhos é de aproximadamente 600 e 1.600 milhões de toneladas, respectivamente. ${ }^{41}$

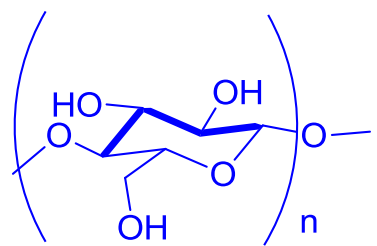

celulose (33)

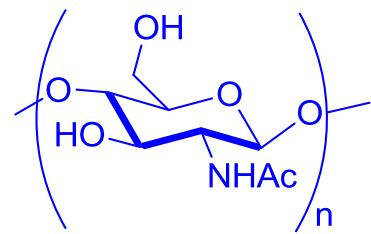

quitina (34)

Figura 9. Celulose (33) e quitina (34)

A madeira é a principal fonte industrial de celulose. Ela é constituída pelos componentes: hemicelulose (20 a $25 \%$ ), celulose (40-50 \%) e lignina ( 25 a $30 \%$ ), além de componentes inorgânicos. A reatividade da celulose é influenciada pela organização cristalina que controla $o$ acesso de substâncias químicas ou enzimas aos grupos 
funcionais e às ligações químicas nas regiões cristalinas. A hidroxila é o grupo mais abundante na molécula de celulose, seguida pelas ligações acetal que formam o anel das piranoses. Um dos grandes desafios atuais é transformar $10 \%$ da celulose produzida pelas florestas em combustíveis e materiais biodegradáveis.

A pirólise da celulose a temperaturas acima de $300{ }^{\circ} \mathrm{C}$ provoca a sua degradação em bio-óleo, através de diversas reações, gerando uma mistura composta por anidrooligossacarídeos, levoglucosana e outros açúcares anidros monoméricos, furanos, ciclopentanonas, piranos e outros derivados. Em resumo, o bio-óleo é uma mistura complexa de água e centenas de compostos orgânicos pertencentes aos grupos dos ácidos carboxílicos, aldeídos, cetonas, álcoois, ésteres, carboidratos anidros, furanos, fenóis, guaiacóis, compostos nitrogenados e oligômeros. Entretanto, é possível controlar o processo de modo a diminuir o número de compostos gerados. ${ }^{42}$ Por exemplo, a levoglucosenona (35) é um intermediário bastante útil em diversas áreas da síntese orgânica e pode ser obtida facilmente obtida a partir da celulose (Esquema 8). O grupo de Spanevello explorou o uso dessa substância em síntese assimétrica. ${ }^{43,44}$

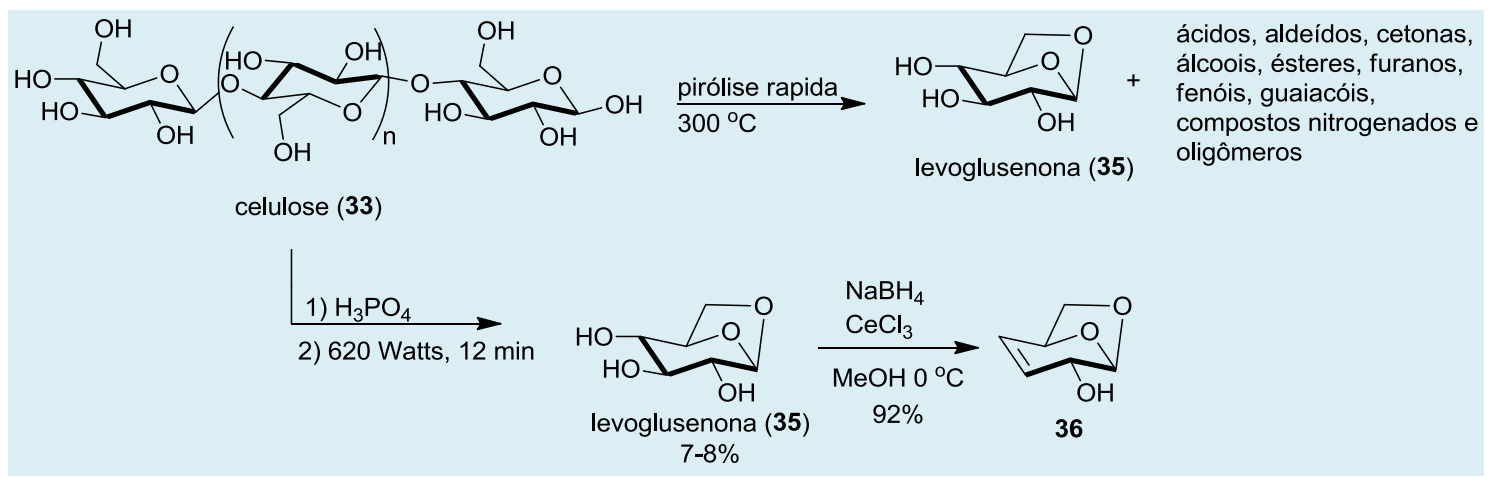

Esquema 8. Obtenção de levoglucosenona (35) por pirólise da celulose

Existem muitos desafios relacionados à conversão da biomassa lignocelulósica, à compreensão do mecanismo de conversão em bio-óleo e à distribuição de produtos e, consequentemente, em sua produção em larga escala.

Outra biomassa que merece destaque é o dissacarídeo mais abundante na natureza, a sacarose (38) (D-glicose + D-frutose). ${ }^{45-47}$ A DSacarose e D-glicose (38 e 36 ) são os principais carboidratos de baixa massa molecular utilizados para alimentação e preparação de intermediários da Química Fina, sendo o Brasil seu maior produtor (em 2010/2011 a produção foi cerca de 38,7 milhões de toneladas) ${ }^{48}$ e com perspectivas de crescimento.

A sacarose (35) é conhecida genericamente com o nome de açúcar e está distribuída em todo o reino vegetal, sendo o principal carboidrato de reserva de energia e material indispensável para a dieta humana. Não existe uma compilação do número de processos que usam a sacarose como matéria-prima, porém sabe-se que há cerca de 100 processos utilizados em escala comercial.

O seu uso como reagente químico tem basicamente três grandes estratégias. A mais comum é a transformação radical da sua estrutura, por meio de processos químicos ou bioquímicos, como pode ser visto no Esquema 9. ${ }^{49,50}$ Muitos produtos são obtidos em escala industrial, sendo o mais conhecido e de maior escala o etanol. ${ }^{51}$ Este álcool é a principal entrada na sacarose na indústria de derivados similares aos obtidos pela indústria petroquímica (exemplo eteno, acetaldeído, acetato de etila, anidrido acético, butanol, 
etc.). Outras possibilidades são a manutenção da estrutura carbônica com pequenas modificações nas hidroxilas ou isomerização da ligação glicosídica.

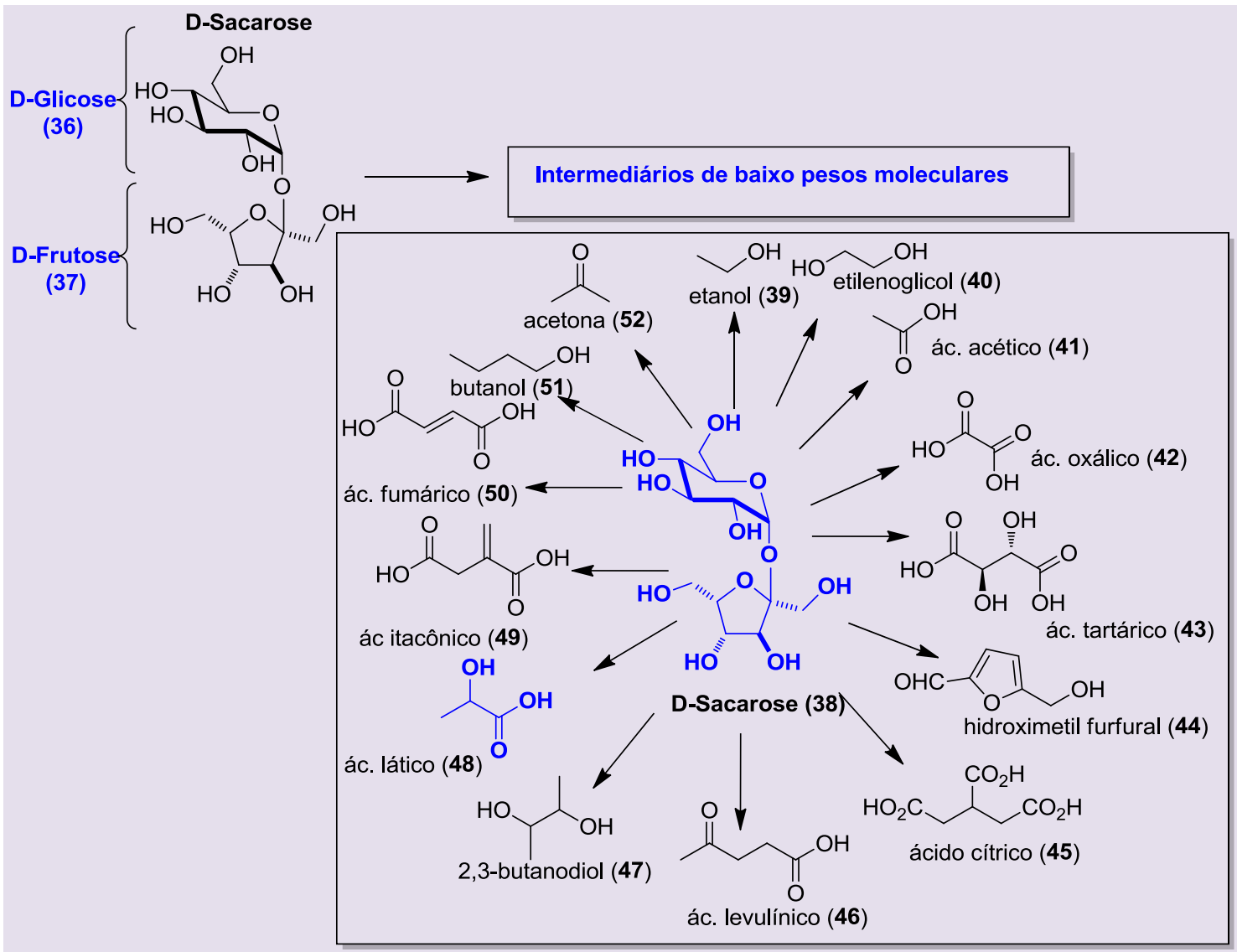

Esquema 9. D-sacarose (38) e exemplos de usos na produção de intermediários sintéticos

O ácido lático (45) pode ser obtido a partir da sacarose (35) ou da glicose (50) (Esquema 10), sendo matéria prima de uma plataforma para outros produtos da Química Fina, como mostrado no Esquema 10. Atualmente, seu uso principal é como polímero, o ácido polilático ou PLA ou $\operatorname{Ingeo~}^{\mathrm{TM}}$. O PLA é biodegradável e se reverte em menos de 4560 dias em condições ideais de compostagem. Ele pode ser usado na confecção de garrafas, copos de iogurte e doces, sacos de resíduos de alimentos, revestimentos de papel e papelão, fibras para vestuário, tapetes, lençóis e toalhas, revestimentos de parede, suturas, materiais protéticos, embalagens de alimentos, aplicações agrícolas, implantes cirúrgicos e suturas, etc. PLA é ainda mais caro do que muitos plásticos de produtos derivados do petróleo, mas seu preço vem caindo com novas aplicações.

O uso de biomassa renovável também pode gerar resíduos aproveitáveis para fins alimentares, para humanos e animais em geral (resíduos de proteínas) e energéticos. Esses resíduos são muitos e diversificados, conforme apresentado na Tabela 1. 


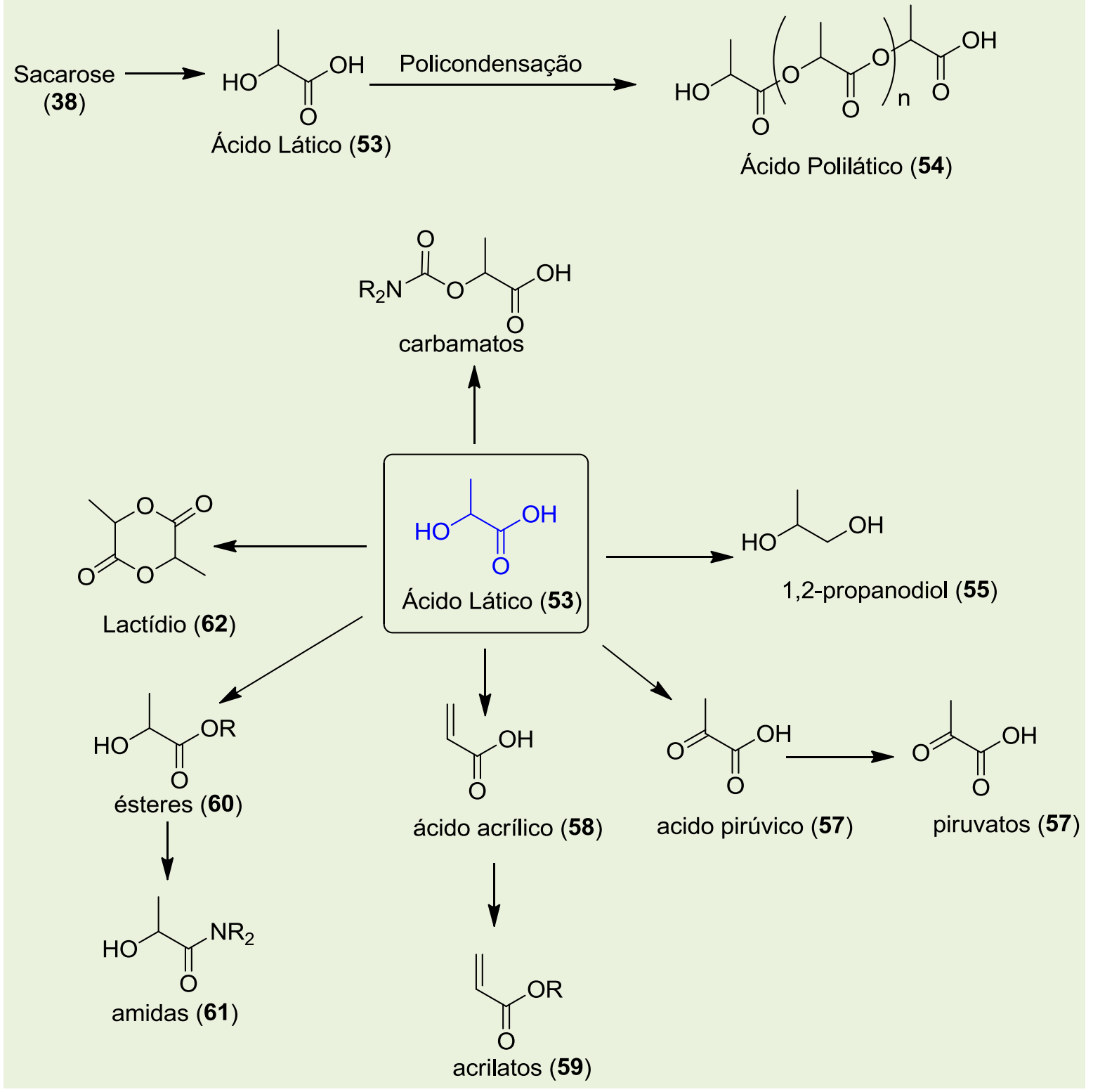

Esquema 10. Plataforma do ácido lático

Tabela 1. Resíduo de biomassa com potencial econômico

\begin{tabular}{|c|c|}
\hline Resíduos & Quantidade (milhões de toneladas /ano) \\
\hline Coco & 5 (Brasil) \\
\hline Bagaço de laranja & 15 (mundo) \\
\hline Casca de Arroz & 220 (mundo) \\
\hline Bagaço de cana & 22 (Brasil) \\
\hline Pó de café & 3 (Europa) \\
\hline Glicerol & $0,260(2010$, Brasil) \\
\hline
\end{tabular}

O bagaço da cana de açúcar é o maior resíduo da agroindústria e representa um terço do peso da cana. Com a estimativa de que o consumo mundial de álcool combustível passará dos 26 bilhões de litros atuais para 205 bilhões em 2025, é um resíduo em franca tendência de acúmulo. Do suco da cana é obtido a sacarose ou o etanol. 
O bagaço pode ser utilizado na alimentação animal, mas a maior parte é queimada para a geração de energia elétrica. Em tese, essa queima não traz qualquer impacto ambiental negativo, porque recoloca no ambiente o $\mathrm{CO}_{2}$ obtido da fotossíntese.

O Brasil tem devotado muito esforço em pesquisas para o chamado "etanol de segunda geração","53 ou etanol celulósico, produzido a partir da palha e do bagaço da cana-de-açúcar. A primeira geração de etanol tem tecnologias bem estabelecidas para algumas culturas, mas o desenvolvimento de processos relacionados à utilização da biomassa de madeira ainda está em fase inicial da investigação e desenvolvimento. Estima-se que será possível triplicar a produção de etanol no Brasil sem aumentar a área plantada de cana de açúcar.

Não é o nosso objetivo aqui fazer um grande levantamento de todos os resíduos derivado de biomassas e que tem um potencial industrial. Ainda assim, cabe destacar que o coco apresenta inúmeras vantagens na sua utilização após a extração da água. Ele é um material ecológico e facilmente reciclável. Um copo de $250 \mathrm{~mL}$ de água de "Coco Verde" gera mais de $1 \mathrm{Kg}$ de resíduo, que corresponde a cerca de $85 \%$ do peso do fruto. ${ }^{54}$

Outro resíduo importante vem das frutas cítricas, que são amplamente produzidas em todo o mundo. Em 2010/11, foram produzidas 85 bilhões de toneladas de frutas cítricas (laranja, tangerina, limão, lima, toranja, etc.) pelos maiores produtores de frutas cítricas, que são Brasil e EUA. Estima-se que 31,2 milhões de toneladas de citros são processados a cada ano no mundo, produzindo 15,6 milhões toneladas de resíduos, ou seja, $50 \%$ do fruto. Nessa grande quantidade de resíduos tem-se limonoides e flavonoides, pectina celulose, glicose, frutose e sacarose. O desafio é desenvolver novos processos para a utilização desses componentes, em um processo integrado e com eficiência. O Dlimoneno é um dos componentes com maior potencial químico e valor agregado. Ele tem amplo uso na perfumaria e em produtos de limpeza. Atualmente, também tem sido considerado como solvente verde em substituição aos tradicionais solventes aromáticos, tais como o tolueno. 0 limoneno é uma molécula que pode ser uma bioplataforma para a preparação de outras substância úteis na Química Fina. ${ }^{55}$

\section{A transformação do modo de vida com o uso dos biocombustíveis}

Os lipídios são substâncias hidrófobicas em cuja composição encontram-se principalmente ésteres derivados de ácidos carboxílicos de cadeias longas (ácidos graxos) e alcoóis triidroxilados. São fundamentais para o metabolismo dos organismos vivos e reserva energética para os organismos. Também são conhecidos como matérias graxas, gorduras e ceras. Eles podem existir também na forma de mono e diglicerídeos e não necessariamente as três unidades de ácidos graxos que compõem um triglicerídeo precisam ser idênticas (Figura 10).

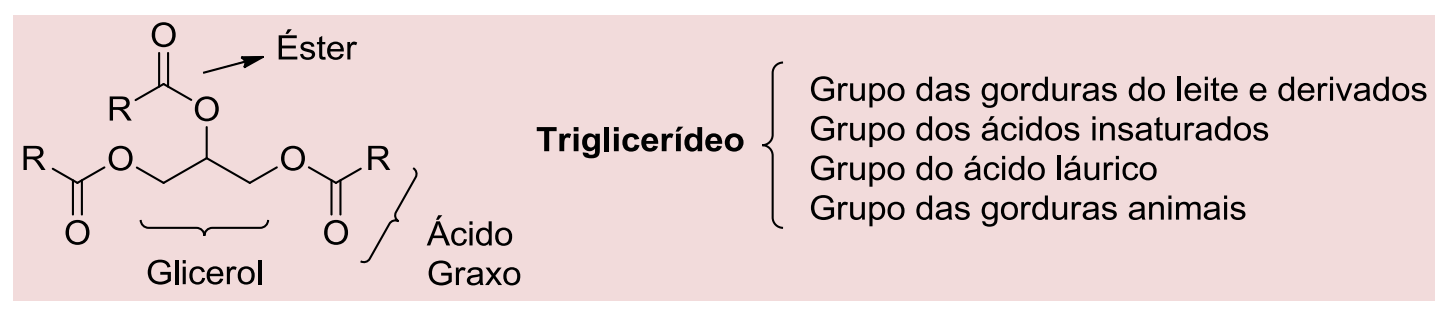

Figura 10. Estrutura geral dos lipídios 
Os biocombustíveis (lenha, palha, óleos, biodiesel, etanol, bioquerosene) são materiais energéticos obtidos de óleos vegetais (ou lipídios) e matérias gordurosas, biomassa de fontes renováveis. Apesar de serem destinados principalmente para produção de energia, alguns tem rotas independentes na produção de intermediários da Química Fina, como é o caso do etanol, que pode ser transformado em diversos produtos. Os biocombustíveis representam a captação de energia solar e sua estocagem em energia contida nas ligações químicas. Sua combustão não aumenta os níveis de $\mathrm{CO}_{2}$ na atmosfera e são obtidos a partir de diversas biomassas: cana de açúcar, milho, oleaginosas e resíduos agropecuários, dentre outras fontes.

Atualmente, o biodiesel é um complemento do óleo diesel, mas que poderá substituí-lo no futuro. Desde 2004, quando entrou em vigor o Programa Nacional de Produção e Uso do Biodiesel (Lei 11.097 de
13 de janeiro de 2005), a percentagem de adição do biodiesel ao óleo diesel é de $5 \%$, mas o governo já estuda um novo marco regulatório a fim de fixar nova percentagem de mistura obrigatória ao diesel comum. A perspectiva é que deverá subir para $10 \% \mathrm{em}$ 2014 e chegar a 20 \% em 2020.

O Brasil é um dos maiores produtores de biodiesel no mundo, utilizando 60 usinas instaladas no país. Em 2011, produziu 2,7 bilhões de litros movimentando US\$ 6,5 bilhões. $\mathrm{O}$ biodiesel é composto por ésteres metílicos ou etílicos de ácidos graxos e sua obtenção ocorre a partir de óleos ou matérias gordurosas através de uma reação de transesterificação com metanol ou etanol (Esquema 11). Os óleos dessa cadeia são as plantas oleaginosas, como a soja (Glycine max), o dendê (Elaeis guineensis), o algodão (Gossypium spp. L.), o girassol (Helianthus annuus), a mamona (Ricinus communis), a macaúba (Acrocomia aculeata) e o pinhão manso (Jatropha curcas). ${ }^{56,57}$

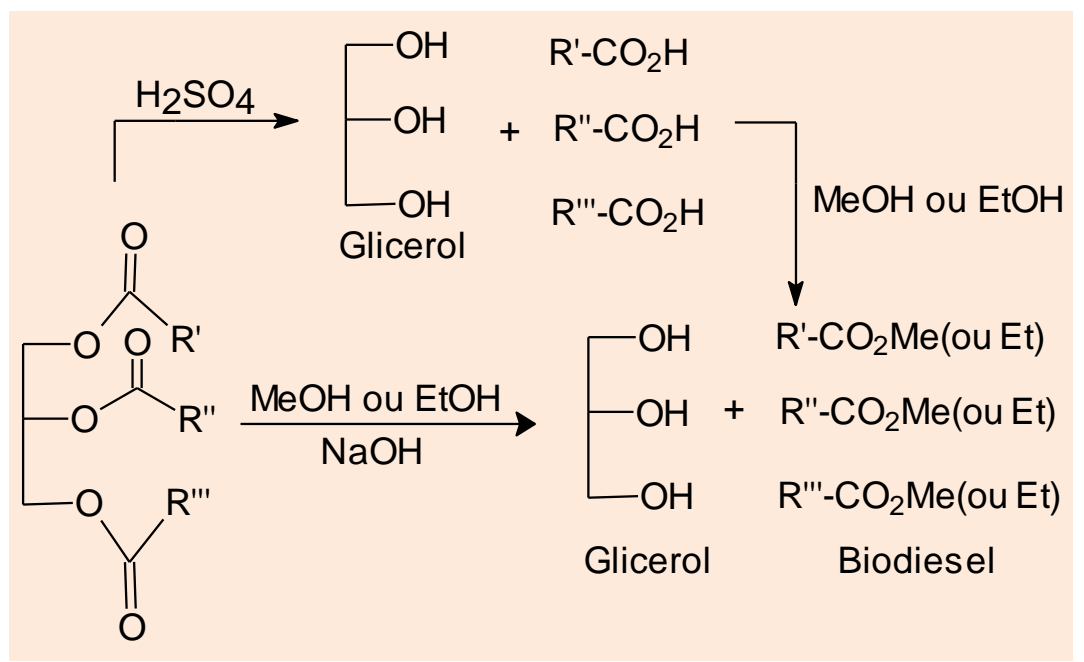

Esquema 11. Transesterificação do óleo vegetal com metanol ou etanol para produzir biodiesel

Com a produção crescente de biodiesel surgiu o problema do aproveitamento do resíduo glicerol, produzido na proporção de 1 $\mathrm{kg}$ para cada $10 \mathrm{~kg}$ de biodiesel. O que era, aparentemente, um enorme problema, passou a ser uma grande oportunidade de desenvolvimento de novos produtos e processos. Várias pesquisas foram, e continuam sendo, desenvolvidas no mundo em torno de um produto com maior valor agregado. Em 2010, sua produção atingiu cerca de $260 \mathrm{mil}$ toneladas apenas como subproduto do biodiesel, volume quase oito vezes superior à demanda, estimada em cerca de $40 \mathrm{mil}$ toneladas. Os principais estudos para seu aproveitamento envolvem seu uso in natura (plastificante, bioplásticos para fabricação de embalagens descartáveis, 
agregante de partículas, cosméticos, etc.) e como reagente químico através de diversas transformações na cadeia $C-3 .{ }^{58-63}$ No
Esquema 12 estão mostrados alguns exemplos de transformação do glicerol em intermediários da cadeia C-3. ${ }^{64}$

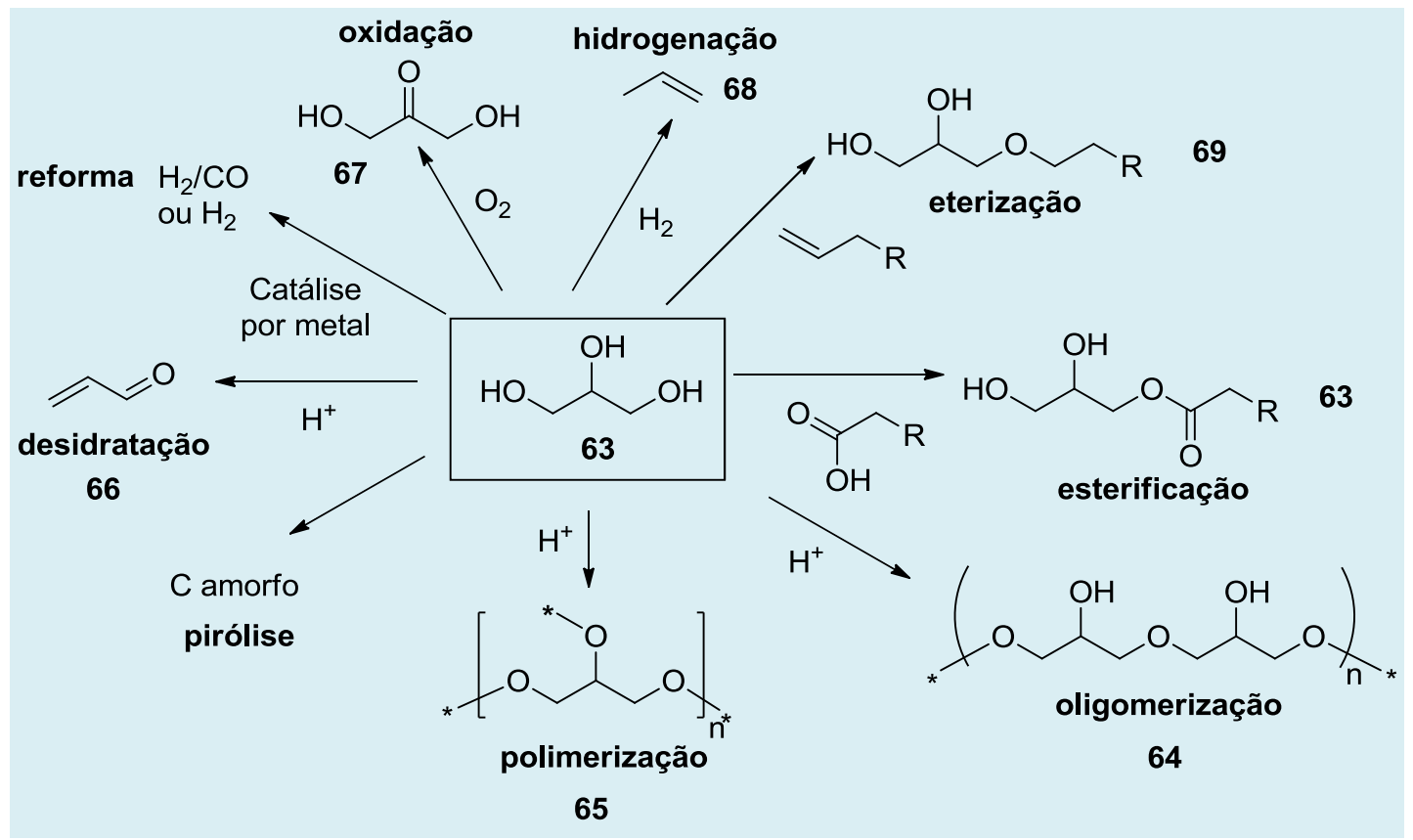

Esquema 12. Exemplos de transformação do glicerol em outros intermediários da cadeia C3

\section{A Talidomida e a revolução dos fármacos}

No início da década de 1960, a constatação dos efeitos teratogênicos provocados pela ( \pm )-talidomida (Figura 10) em gestantes nos três primeiros meses de gravidez, e que afetou pelo menos dez mil bebês, representou um marco na conscientização do risco da administração de um fármaco em sua forma racêmica. Através de técnicas de resolução cromatográfica e da administração dos enantiômeros, ficou constatado que o efeito teratogênico da talidomida era proveniente do enantiômero de configuração absoluta $(S)$, enquanto seu epímero era desprovido de ação teratogênica. ${ }^{65}$ No entanto, mesmo a administração oral de sua forma enantiomericamente pura não evitaria a tragédia devido a sua rápida epimerização no plasma humano. ${ }^{65}$

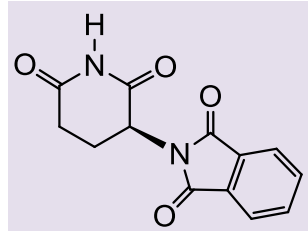

(S)-Talidomida (70) Atividade teratogênica

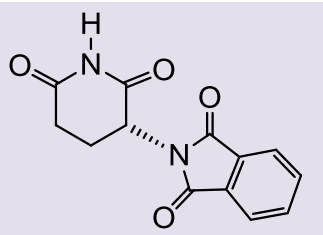

(R)-Talidomida (71)

Usada contra enjoo gestacional

Figura 10. Enantiômeros da Talidomida 
Os efeitos desastrosos da Talidomida despertaram a sociedade para os riscos dos medicamentos e sua segurança se tornou tema de interesse internacional, fazendo com que as autoridades governamentais adotassem nova postura diante do risco de produtos farmacológicos.

Desta forma, surgiu o conceito de Farmacovigilância que, segundo a definição da Organização Mundial de Saúde (OMS), compreende a ciência e as atividades relacionadas à detecção, avaliação, compreensão dos efeitos adversos ou outros problemas relacionados aos medicamentos. Trata-se de um sistema que cuida das informações de segurança dos medicamentos comercializados. A Farmacovigilância não é somente responsabilidade da indústria, mas, sobretudo, do governo com a população, do médico com o paciente e da indústria com os seus consumidores, ou seja, de todos aqueles que estão envolvidos de algum modo na regulamentação, desenvolvimento, produção e comercialização de medicamentos.

\section{Práticas passadas e algumas desastrosas}

Apesar das muitas contribuições da Química para melhorar a nossa qualidade de vida, não é essa a ideia geralmente transmitida ao público. Muitas pessoas ainda veem a Química e a indústria química como nocivas para o ambiente e para as pessoas. A palavra química passou, em muitos casos, a ter conotação negativa e a ser sinônima de chaminés fumegantes e rios envenenados. Um exemplo claro desta dicotomia são os defensivos agrícolas, que contribuem enormemente para ampliar a agricultura e, consequentemente, alimentar o mundo. A ideia dos alimentos orgânicos cultivado sem produtos químicos, incapaz de atender a demanda da população mundial crescente, destacou-se a partir dos problemas de toxidez causados pelo mau uso dos defensivos agrícolas.

O simples ato de tratar o cabelo também passou a ter conotação nociva. O excesso de produtos utilizados para fins de embelezamento dos cabelos tem criado diversos problemas. Diz-se nos salões de beleza jargões como "química mal retirada dos fios", "química incompatível com a química anterior". Essa preocupação é pertinente, haja vista a lista de produtos que são utilizados: tiometaclilato, guanidina, hidróxido de sódio, monoetanolamina, amônia, água oxigenada, formol, derivados de silicone, tinturas, corantes etc. Os exemplos anteriores mostram apenas uma fração dos produtos químicos em uso nos salões de beleza, sendo necessária uma abordagem mais abrangente para reduzir ou eliminar os mais tóxicos e conscientizar o cidadão sobre seus perigos.

Na realidade, a população conhece pouco sobre a maioria dos produtos químicos utilizados no comércio. Muitos produtos têm regulamentação para sua composição e uso, mas é necessário mais rigor para assegurar a responsabilidade dos produtores e a eficácia do produto, a exemplo dos retardadores de chama e plastificantes, de teor de chumbo em velas, dos produtos com amianto, dos corantes tóxicos, etc. Algumas cidades, como a de São Francisco (EUA), estão tomando decisões políticas na esfera local, levando a uma verdadeira colcha de retalhos quanto a regulação química dos produtos.

O Prof. Oswaldo L. Alves tem uma consideração bastante interessante: "Talvez seja essa onipresença que, por vezes, contribui para fazer a Química mal-amada pelas mídias, amiúde preocupadas mais em focalizar suas manifestações negativas e visíveis: fumaça das fábricas, poluição, etc., deixando de iluminar o universo amplo de seus aspectos positivos". ${ }^{66}$

De certa forma, episódios desastrosos no passado recente continuam ocorrendo em muitos países, como a China, que tem destroçado seu meio ambiente para alavancar a indústria química. Porém, com o avanço dos meios de comunicação e, principalmente, da internet, a opinião pública se tornou muita afinada e alerta quanto aos efeitos de práticas não recomendáveis para 
um ambiente sustentável. Hoje, é possível denunciar más práticas em teleatendimentos, blogs, serviços de defesa do consumidor, através de redes sociais como Twiter, Facebook e outras ferramentas tecnológicas.

Apesar das questões ambientais fazerem parte permanente da mídia e seja tema exaustivo em escolas, é primordial a conscientização da população em práticas simples do dia a dia, mas de grande impacto para uma vida sustentável. O uso de materiais descartáveis que são perenes no meio ambiente, o consumismo que cresce a cada dia e o uso individual de veículos automotores são alguns dos exemplos mais pertinentes. Parecem ações simples, mas deveras impactantes para um planeta que está próximo a exaustão.

Dois exemplos interessantes demonstram que é possível mudar as práticas equivocadas por outras mais recomendáveis. Anteriormente, a limpeza de roupas a seco era feita com gasolina e querosene. Em seguida, foi introduzido o percloroetileno, que passou a ser o produto de escolha para limpeza de roupas a seco e também como desengordurante em várias indústrias. Mais tarde, descobriu-se que ele é suspeito de causar câncer e sua disposição pode contaminar águas subterrâneas. Um novo método mais seguro de lavagem a seco faz uso do $\mathrm{CO}_{2}$ líquido, que é um solvente mais seguro e ótimo para dissolver gordura. Este método ainda não está sendo usado em todos os estabelecimentos para limpeza a seco, mas é uma mudança de paradigma. Outro exemplo foi a redução da presença de chumbo em tintas e a eliminação do tetraetilchumbo como aditivo na gasolina.

Com o intuito de esclarecer aspectos da imagem negativa da Química, cabe ainda destacar alguns incidentes com produtos químicos que foram bem divulgados na mídia nas últimas décadas (Tabela 2).

Tabela 2. Incidentes envolvendo a atividades químicas e os danos

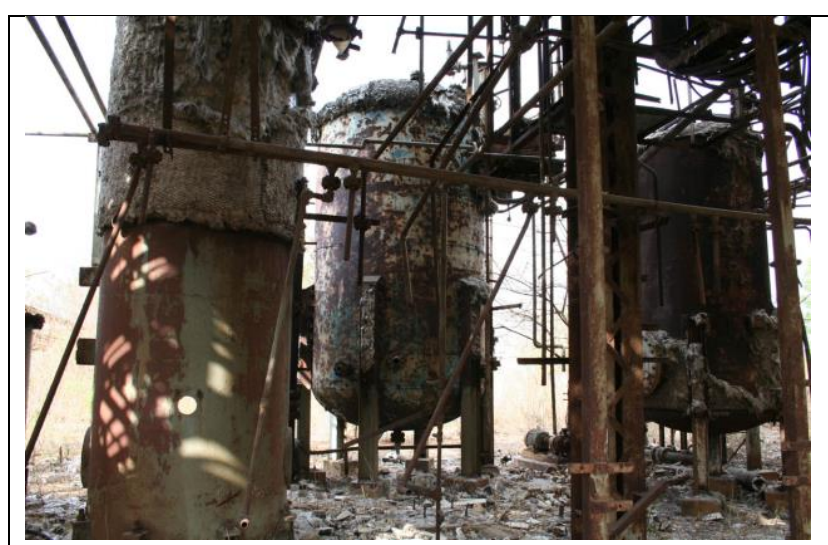

Acidente de Bhopal, Índia, 3 de dezembro 1984. O isocianato de metila ("MIC", $\mathrm{CH}_{3} \mathrm{NCO}$ ) utilizado na fabricação de carbaril $\left(\operatorname{Sevin}^{\circledR}\right.$ ) pela Union Carbide. Foi incorporada água num tanque de armazenamento contendo 15 toneladas de $\mathrm{MIC}$, levando a seguinte reação: $\mathrm{CH}_{3} \mathrm{NCO}+\mathrm{H}_{2} \mathrm{O} \rightarrow \mathrm{CH}_{3} \mathrm{OH}+\mathrm{HNCO}$. A válvula de pressão explodiu, o purificador de backup e a torre de queima (flaretower) não entraram em operação. $O$ resultado foi a liberação de toneladas de MIC vaporizado, que foi espalhado pelo vento e levou vapor através da cidade. Pelo menos 3.800 pessoas morreram, milhares ficaram feridos e cegos.

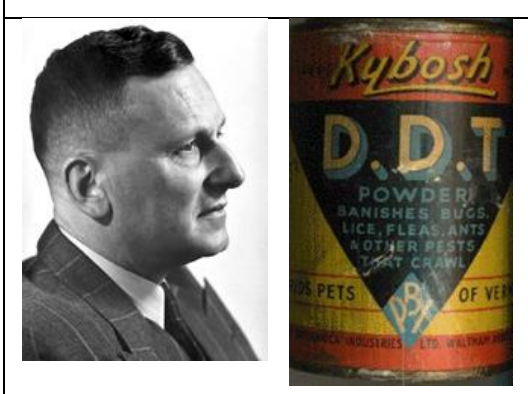

O milagroso DDT. O DDT foi sintetizado pela primeira vez em 1874, no laboratório do Adolf von Baeyer, da Universidade de Strasbourg(Prêmio Nobel de Química em 1905, por suas contribuições para o desenvolvimento da química orgânica), a partir da condensação de hidrato de cloral com clorobenzeno, em ácido sulfúrico concentrado. Sua habilidade como inseticida foi percebida por Paul Muller, em 1939, contra as traças e besouros (Prêmio Nobel em 1948 pela descoberta do uso do DDT contra insetos). Por ser barato e seguro para aplicação na pele 


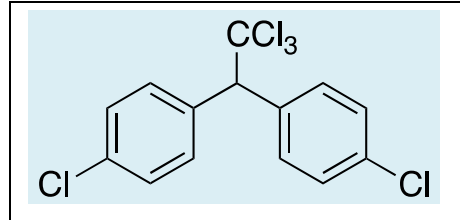

humana, o DDT foi muito usado durante a Segunda Guerra Mundial para controlar a malária, tifo e outras doenças transmitidas por insetos. Posteriormente, tornou-se um dos mais utilizados agroquímicos do mundo. Vários bilhões de quilos de DDT foram fabricados e utilizados entre 1940 e início de 1970 . O uso do DDT foi proibido nos Estados Unidos em 1972 e seus efeitos cumulativos permanecem até hoje.

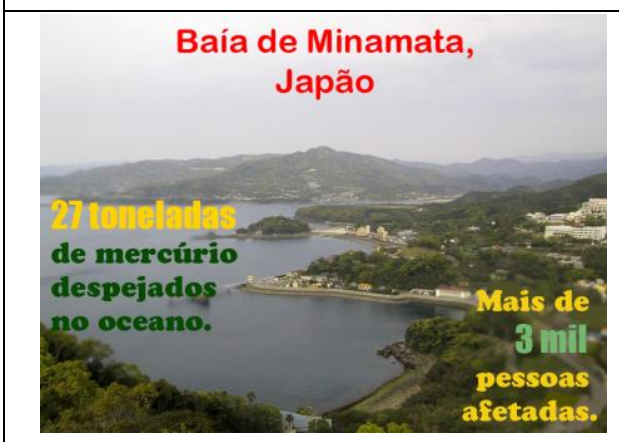

A doença de Minamata. ${ }^{67}$ Minamata é uma ilha localizada no Japão, na costa do Mar Shiranui. Inicialmente, relatos descreviam que os gatos pareciam estar enlouquecendo e cometiam suicídio. Logo depois, as pessoas da cidade também passaram a apresentar comportamentos estranhos, com dificuldade de ouvir, ver e caminhar, tremores e danos cerebrais. $O$ problema foi elucidado e relacionado às 27 toneladas de compostos orgânicos de mercúrio despejadas no mar, pela planta petroquímica Chisso Corporation, desde 1930, e que foram absorvidas por toda cadeia alimentar da ilha.

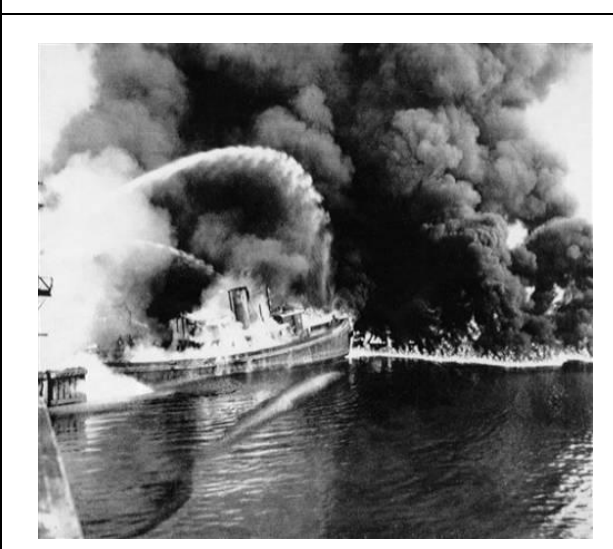

Fogo no Rio Cuyahoga. O rio Cuyahoga, em Ohio, nos EUA, tornou-se tão poluído por produtos químicos que pegou fogo várias vezes, desde 1868 até 1969. O incêndio mais potente ocorreu em 1952, que causou mais de US $\$ 1,3$ milhão em danos. O fogo mais fatal aconteceu em 1912, causando cinco mortes. O estado de Ohio é, até os dias de hoje, considerado o centro da indústria americana, com indústrias de aço, automobilísticas e agrícolas tradicionais instaladas lá. Apesar dos percalços, o rio Cuyahoga foi recuperado, e o estado é hoje um modelo de desenvolvimento em pesquisas na área de energia solar e tecnologias verdes.

\section{Conclusões}

A Química pode ser muito boa e contribuir para resolver os problemas graves que afetam a humanidade. Mas também pode ser o outro lado da moeda. Mas a Química é feita pelo ser humano, e assim cabe ao mesmo responder a seguinte pergunta: qual o modelo de desenvolvimento que queremos?

Em nossa opinião, desejamos fármacos seguros, terapeuticamente equivalentes (no caso dos genéricos), com controle de qualidade eficiente e permanente, sem pirataria ou uso de matérias primas "marrons", preparados por rotas verticalizadas nas farmoquímicas brasileiras ou com insumos produzidos nas indústrias químicas brasileiras. Estes processos devem seguir rotas ambientalmente recomendáveis, com matérias primas oriundas de fontes renováveis e processos sustentáveis. Devemos buscar medicamentos para doenças antes consideradas incuráveis; produtos químicos que fertilizam a terra sem agredi-la; eliminar resíduos tóxicos industriais; gerir o esgoto e lixo doméstico e evitar a qualquer custo a poluição. Devemos ainda dar proteção ao consumidor através de produtos químicos seguros, que tragam qualidade aos alimentos, produtividade nas plantações, combustíveis não-poluentes e de alto rendimento energético e, finalmente, com trabalhadores recebendo salários compatíveis com as suas qualificações. Sendo 
assim, é muito importante o fortalecimento da Química através da pesquisa e com profissionais que possam executá-la com responsabilidade, para que possamos ter qualidade compatível com o ambiente e a natureza. Entretanto, é triste constatar que ainda existe a fome no mundo, que 1 bilhão de pessoas não têm acesso a água potável de boa qualidade e que 1,3 bilhão vivem em locais em que a qualidade do ar é imprópria. Esse é o anti-modelo que queremos.

A Química é apontada por muitos como vilã nas agressões à natureza, mas pelo exposto ela é fértil em soluções que podem melhorar a qualidade de vida do Homem.

\section{Referências Bibliográficas}

${ }^{1}$ Boethling, R. S.; Sommer, E.; DiFiore, D. Designing Small Molecules for Biodegradability. Chemical Reviews 2007, 107, 2207. [CrossRef] [PubMed]

${ }^{2}$ Metcalf, R. L. Century of DDT. Journal of Agricultural and Food Chemistry 1973, 21, 511. [CrossRef] [PubMed]

${ }^{3}$ Anastas, P. T.; Warner, J.; Green Chemistry: Theory and Practice, Oxford University Press: Oxford, 1998.

${ }^{4}$ de Torresi, S. I. C.; Pardini, V. L.; Ferreira, V. F. O que é sustentabilidade? Química Nova 2010, 33, 5. [CrossRef]

${ }^{5}$ Sítio da Xperimania. Química e Ambiente: Ajuda ou Obstáculo? Disponível em: $<$ http://www.xperimania.net/ww/pt/pub/xp erimania/news/world of materials/chemistr $\mathrm{y}$ and the environment.htm $>$. Acessado em: 30 janeiro 2013.

${ }^{6}$ Sítio da Associação Brasileira da Indústria Química (Abiquim). Disponível em: <http://abiquim.org.br/vceaquim/vida.ht $\mathrm{ml}>$. Acessado em: 30 janeiro 2013.

${ }^{7}$ da Silva, L. A.; de Andrade, J. B. Química a Serviço da Humanidade. Química Nova na Escola 2003, 5, 3. [Link]
${ }^{8}$ Sítio da Sociedade Brasileira de Química. Disponível em: <http://www.sbq.org.br/26ra/eliezer.htm>. Acessado em: 27 dezembro 12.

${ }^{9}$ Ferreira, V. F. Química é sempre boa. Química Nova 2007, 30, 255. [CrossRef]

${ }^{10}$ Anuário da Associação Brasileira das Indústrias Químicas, ABIQUIM, 2012. [Link]

${ }^{11}$ Mello, V. M.; Suarez, P. A. Z. As formulações de Tintas Expressivas Através da História. Revista Virtual de Química 2012, 4, 2. [Link]

12 Fiedler, H. INCT Catálise. Science for all, Ciência para todos. Disponível em: $<$ http://scienceforallinctbrasil.blogspot.com>. Acessado em: 30 janeiro 2013.

${ }^{13}$ Paddon, C. A.; Atobe, M.; Fuchigami, T.; He, P.; Watts, P.; Haswell, S. J.; Pritchard, G. J.; Bull, S. D.; Marken, F. Towards paired and coupled electrode reactions for clean organic microreactor electrosyntheses. Journal of Applied Electrochemistry 2006, 61, 617. [CrossRef]

${ }^{14}$ Augustine, J. K.; Bombrun, A.; Atta, R. N. A Practical and Cost-Efficient, One-Pot Conversion of Aldehydes into Nitriles Mediated by 'Activated DMSO'. Synlett 2011, 2223. [CrossRef]

${ }^{15}$ Ferreira, V. F.; da Silva, F. C. Metátese em Síntese Orgânica e o Prêmio Nobel de Química de 2005: Do Plástico à Indústria Farmacêutica. Química Nova na Escola 2005, 22, 3. [Link]

${ }^{16}$ Biggs-Houck, J. E.; Younai, A.; Shaw, J. T. Recent advances in multicomponent reactions for diversity-oriented synthesis. Current Opinion in Chemical Biology 2010, 14, 371. [CrossRef]

${ }^{17}$ Shaabani, A.; Maleki, A; Rezayan, A. H.; Sarvary, A. Recent progress of isocyanidebased multicomponent reactions in Iran. Molecular Diversity 2011, 15, 41. [CrossRef] 
18 Batalha, P. N. Recentes Avanços em Reações Multicomponentes: Uma Perspectiva Entre os Anos de 2008 e 2011. Revista Virtual de Química 2012, 4, 13. [Link] 19 Damasceno, V. Guerra aos sintéticos ressuscita os naturais. Química e Derivados 1988, 10.

${ }^{20}$ da Rocha, D. R.; Ferreira, V. F.; Santos, W.

C. Aspectos da Síntese Orgânica no Desenvolvimento de Métodos e de Moléculas Biologicamente Ativas. Revista Processos Químicos 2008, 2, 9. [Link]

21 Pinto, A. C., O Pau-brasil e um pouco da história brasileira. Disponível em: <http://www.sbq.org.br/filiais/adm/Upload/s ubconteudo/pdf/Historias_Interessantes_de_ Produtos_Naturais07.pdf >. Acessado em: 30 janeiro 2013.

22 Pinto A. C. O Brasil dos viajantes e dos exploradores e a química de produtos naturais brasileira. Química Nova 1995, 18, 608. [Link]

23 Bueno, E.; Coleção Terra Brasilis, Vol. V.II, Objetiva: Rio de Janeiro, 1998.

24 Henderson, R. K.; Jimenez-Gonzalez, C.; Constable, D. J. C.; Alston, S. R.; Inglis, G. G. A.; Fisher, G.; Sherwood, J.; Binks, S. P.; Curzons, A. D. Expanding GSK's solvent selection guide - embedding sustainability into solvent selection starting at medicinal chemistry. Green Chemistry 2011, 13, 854. [CrossRef]

${ }^{25}$ Simon, M.-O.;Li, C.-J. Green chemistry oriented organic synthesis in water. Chemical Society Reviews 2012, 41, 1415. [CrossRef]

${ }^{26}$ Sheldon, R. A. Utilisation of biomass for sustainable fuels and chemicals: Molecules, methods and metrics. Catalysis Today 2011, 167, 3. [CrossRef]

27 Welton, T. Room-Temperature Ionic Liquids. Solvents for Synthesis and Catalysis. Chemical Reviews 1999, 99, 2071. [CrossRef]

28 Dupont, J.; Consorti, C. S.; Spencer, J. Room Temperature Molten Salts: Neoteric "Green" Solvents for Chemical Reactions and
Processes. Journal of the Brazilian Chemical Society 2000, 11, 337. [CrossRef]

${ }^{29}$ Licence, P.; Ke, J.; Sokolova, M.; Ross, S. K.; Poliakoff, M. Chemical reactions in supercritical carbon dioxide: from laboratory to commercial plant. Green Chemistry 2003, 5, 99. [CrossRef]

${ }^{30}$ Bourne, R. A.; Stevens, J. G.; Ke, J.; Poliakoff, M. Maximising opportunities in supercritical chemistry: the continuous conversion of levulinic acid to $\mathrm{p}$-valerolactone in CO2. Chemical Communications 2007, 4632. [CrossRef]

${ }^{31}$ Han, X.; Poliakoff, M. Continuous reactions in supercritical carbon dioxide: problems, solutions and possible ways forward. Chemical Society Reviews 2012, 41, 1428. [CrossRef] [PubMed]

32 Sítio da AsahiKasei. Disponível em: $<$ http://www.asahi-

kasei.co.jp/asahi/en/services products/>.

Acessado em: 30 janeiro 2013.

${ }^{33}$ Yu, T.; Cristiano, R.; Weiss, R. G. From simple, neutral triatomic molecules to complex chemistry. Chemical Society Reviews 2010, 39, 1435. [CrossRef]

${ }^{34}$ Cokoja, M.; Bruckmeier, C.; Rieger, B.; Herrmann, W. A.; Kuhn, F. E. Transformation of Carbon Dioxide with Homogeneous Transition-Metal Catalysts: A Molecular Solution to a Global Challenge? Angewandte Chemie International Edition 2011, 50, 8510. [CrossRef] [PubMed]

${ }^{35}$ Omae, I. Recent developments in carbon dioxide utilization for the production of organic chemicals. Coordination Chemistry Reviews 2012, 256, 1384. [CrossRef]

${ }^{36}$ Wu, C.; Cheng, H.; Liu, R.; Wang, Q.; Hao, Y.; Yu, Y.; Zhao, F. Synthesis of urea derivatives from amines and $\mathrm{CO} 2$ in the absence of catalyst and solvent. Green Chemistry 2010, 12, 1811. [CrossRef]

${ }^{37}$ Yano, T.; Matsui, H.; Koike, T.; Ishiguro, H.; Fujihara, H.; Yoshihara, M.; Maeshima, T. Magnesium oxide-catalysed reaction of 
carbon dioxide with anepoxide with retention of stereochemistry. Chemical Communications 1997, 1129. [CrossRef]

${ }^{38}$ North, M.; Pasquale, R.; Young, C. Synthesis of cyclic carbonates from epoxides and CO2. Green Chemistry 2010, 12, 1514. [CrossRef]

${ }^{39}$ Júnior, S. V.; Estratégias para o Uso de Biomassa em Química Renovável, Documentos 10, Embrapa Agroenergia, 2012. [Link]

${ }^{40}$ Schuchardt, U.; Ribeiro, M. L.; Gonçalves, A. R. A indústria petroquímica no próximo século: como substituir o petróleo como matéria-prima? Química Nova 2004, 24, 247. [CrossRef]

${ }^{41}$ Cauchie, H. M. Em Advances in Chitin Science; Domard, A.; Roberts, G. A. F.; Varum, K. M., eds.; Jacques Andre: Lyon, 1997.

${ }^{42}$ Stocker, M. Biofuels and Biomass-To-Liquid Fuels in the Biorefinery: Catalytic Conversion of Lignocellulosic Biomass using Porous Materials. Angewandte Chemie International Edition. 2008, 47, 2. [CrossRef] [PubMed]

${ }^{43}$ Sarotti, A. M.; Spanevello, R. A.; Suárez, A.

$G$. An efficient microwave-assisted green transformation of cellulose into levoglucosenone. Advantages of the use of an experimental design approach. Green Chemistry 2007, 9, 1137. [CrossRef]

${ }^{44}$ Sarotti, A. M.; Spanevello, R. A.; Duhayon, C.; Tuchagues, J.-P.; Suárez, A. G. Exploring structural effects of levoglucosenone derived chiral auxiliaries in asymmetric Diels-Alder cycloadditions. Tetrahedron 2007, 63, 241. [CrossRef]

${ }^{45}$ a) Emmons, C. H. H.; Kuster, B. F. M.; Sheldon, R. A. A new convenient method for the synthesis of chiral C3-synthons. Tetrahedron: Asymmetry 1991, 2, 359; [CrossRef] b) Rossiter, B. T.; Swingle, M. M. Asymmetric conjugate addition. Chemical Reviews 1992, 92, 771; [CrossRef] c) Draths, K. M.; Wards, T. L.; Frost, J. M. Biocatalysis and nineteenth century organic chemistry: conversion of D-glucose into quinoid organics. Journal of the American Chemical Society 1992, 114, 9725. [CrossRef]

${ }^{46}$ Strong, L. A. G.; The Story of Sugar, Academic Press: Londres, 1954.

${ }^{47}$ Buchholz, K. E.; Stoppok, E.; Matalla, K.; Reh, K. D.; Jördening, H. -J. Em Carbohydrates as Organic Raw Materials; Lichtenthaler, F. W., ed.; VCH Verlag: New York, 1991.

${ }^{48}$ Sítio da FAO: Food and Agriculture Organization of the United Nations. Disponível em: <http://www.fao.org/docrep/010/ai466e/ai4 66e07.htm>. Acessado em: 12 janeiro 2009. ${ }^{49}$ Willians, R. Em Sucrochemistry: Chemical Fermentation; Gould, R. F., ed.; ACS Symposium Series, 1977.

${ }^{50}$ James, C. E.; Hough, L.; Khan, R. Em Progress in the Chemistry of Organic Natural Products; Herz, W.; Grisebach, H.; Kirby, G. W.; Tamm, Ch., eds.; Springer-Verlag: Wien New York, 1989, 117-184.

${ }^{51}$ Carioca, J. O. B.; Brazilian Network on Green Chemistry: Awareness, Responsibility and Action, UFC: Fortaleza, 2008.

${ }^{52}$ Sítio BiodieselBr. Disponível em: $<$ http://www.biodieselbr.com/noticias/bio/gl icerina-residuo-biodiesel-ganha-novo-

mercado-270910.htm>. Acessado em: 1 fevereiro 2013.

${ }^{53}$ Oliveira, M. Pesquisa FAPESP 2008, (154), 29.

${ }^{54}$ Senhoras, E. M. Revista Urutágua 2004, 5. Disponível em: <http://www.urutagua.uem.br/005/22eco s enhoras.htm>. Acessado em: 1 fevereiro 2012.

${ }^{55}$ Clark, J. H.; Fitzpatrick, E. M.; Macquarrie, D. J.; Pfaltzgraff, L. A.; Sherwood, J. pCymenesulphonic acid: An organic acid synthesised from citrus waste. Catalysis Today 2012, 190, 144. [CrossRef]

Rev. Virtual Quim. |Vol 6| |No. 1| |85-111| 
${ }^{56}$ Santos, A. P. B.; Pinto, A. C. Biodiesel: Uma Alternativa de Combustível Limpo. Química Nova na Escola 2009, 31, 58. [Link]

${ }^{57}$ Beatriz, A.; Araújo, Y. K.; De Lima, D. P. Glicerol: um breve histórico e aplicação em sínteses estereosseletivas. Química Nova 2011, 34, 306. [CrossRef]

${ }^{58}$ Ciriminna, R.; Pagliaro, M. One-Pot Homogeneous and Heterogeneous Oxidation of Glycerol to Ketomalonic Acid Mediated by TEMPO. Advanced Synthesis \& Catalysis 2003, 345, 383. [CrossRef]

${ }^{59}$ Ozorio, L. P.; Pianzolli, R.; Mota, M. B. S.; Mota, C. J. A. Reactivity of glycerol/acetone ketal (solketal) and glycerol/formaldehyde acetals toward acid-catalyzed hydrolysis. Journal of the Brazilian Chemical Society 2012, 23, 931. [CrossRef]

${ }^{60}$ Machado, B. A. S.; Figueirêdo, T. V. B.; Santos, J. C. P.; Reis, J. H. O.; Santana, M. C. C. B.; Druzian, J. I. Cadernos de Prospecção 2012, 5, 1.

${ }^{61}$ Medeiros, M. A.; Lago, R. M. Polimerização do glicerol: uma reação simples e versátil para produzir diferentes materiais a partir do coproduto do biodiesel. Química Nova 2011, 34, 1079. [CrossRef]
62 Mota, C. A.; da Silva, C. X. A.; Gonçalves, V. C. Gliceroquímica: novos produtos e processos a partir da glicerina de produção de biodiesel. Química Nova 2009, 32, 639. [CrossRef]

${ }^{63}$ dos Santos, N. B. L.; Rezende, M. J. C. Produção de Monoacilgliceróis: Rotas e Catalisadores. Revista Virtual Química 2012, 4, 118. [Link]

Zhou, C. H.; Beltramini, J. N.; Fan, Y. X.; Lu, G. Q. Chemoselective catalytic conversion of glycerol as a biorenewable source to valuable commodity chemicals. Chemical Society Reviews 2008, 37, 527. [CrossRef]

${ }^{64}$ Lima, L. M.; Fraga, C. A. M.; Barreiro, E. J. O renascimento de um fármaco: talidomida. Química Nova 2001, 24, 683. [CrossRef] ${ }^{65}$ Alves, O. L., Química: Ciência, Tecnologia e a Qualidade de Vida. Disponível em: <http://Iqes.iqm.unicamp.br/canal_cientifico /pontos_vista/pontos_vista_artigos_opiniao1 6-1.html >. Acessado em: 1 fevereiro 2013. ${ }^{66}$ Sítio do YouTube, Mercury Poisoning- The MinamataStory. Disponível e: $<$ http://www.youtube.com/watch?v=ihFkyPv 1jtU>. Acessado em: 1 fevereiro 2013. 